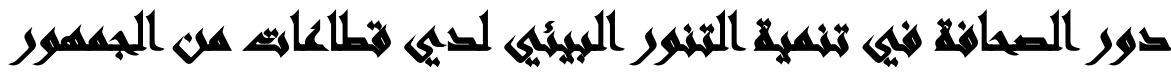

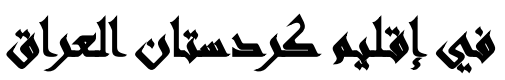

\section{[ $1 \mathrm{~V}]$}

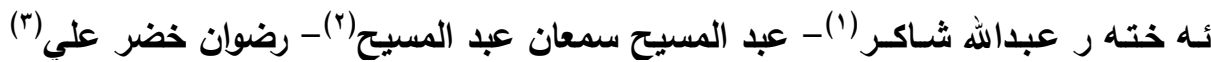

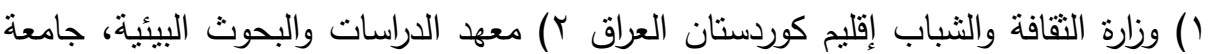

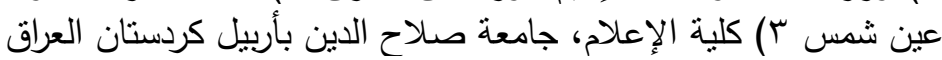

\section{المستخليه}

هدفت الدراسة إلي تحليل القضايا البيئية في بعض الصحف الكردية بكردستان العراق

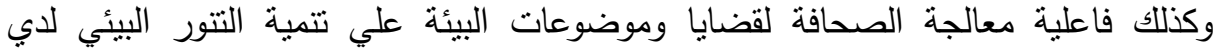

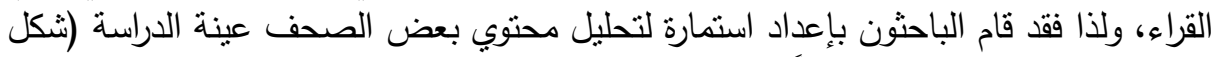

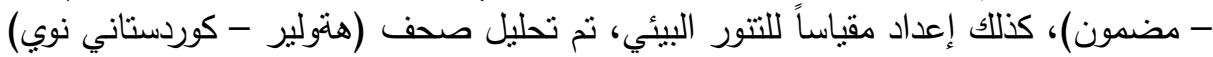

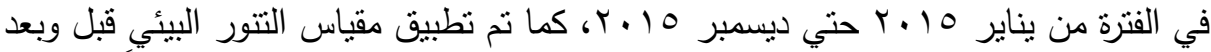
قراءة القضايا البيئية المنشوردة في الجريدنين عينة الدراسة والتي بلغت . ب فرداً واستخدم الباحثون المنهج الوصفي والمنهج شبائه التجريبي.

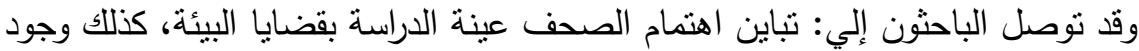

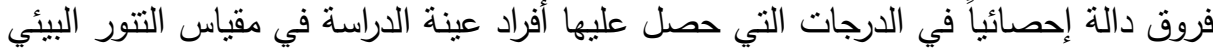

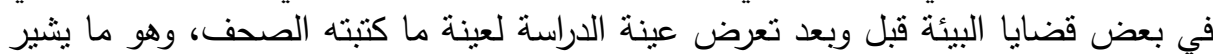

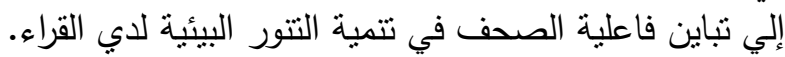

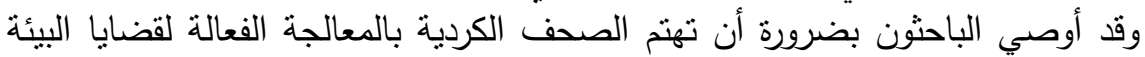
مما ينعكس بالتتور البيئي للقراء.

\section{$\operatorname{san}$}

حظي موضوع البيئة باهنمام المتخصصين والرأي العام خلال منذ أكثر من عقدين وكثرت الموضوعات والدراسات التي تتاولت قضايا البيئة في الصحف، والئ خاصة بعد أن أخذات

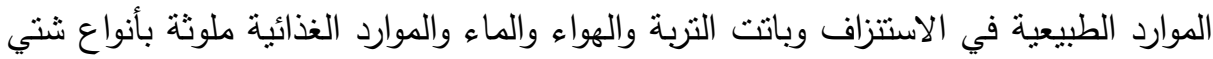
من المواد الكيميائية، الأمر الذي يساهم بدور كبير في زيادة نسبة التلوث لارجة جعلت من تلك القضية واحدة من أهم وأخطر القضايا التي نواجه الإنسان.

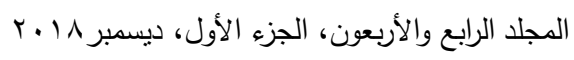


وفي هذا المجال يمكن أن تؤدي وسائل الإعلام - ومنها الصحف والمجلات على وجه

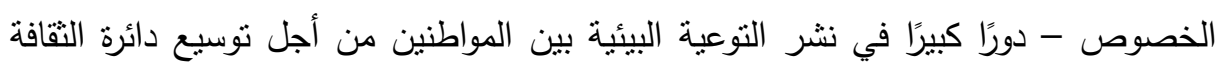

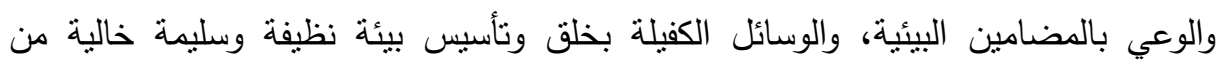

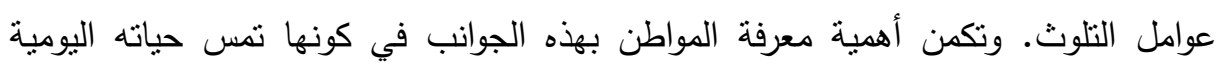
ومستقبله حتى تتكون لديه حصانة وتصور ناضج حول البيئة وكيفية التعامل اليومي معها،

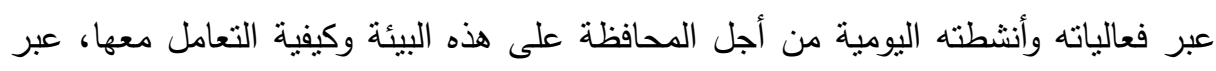

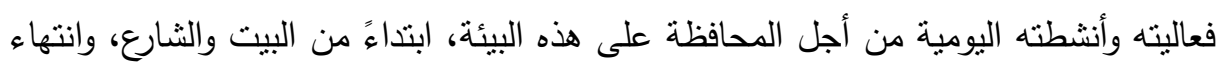

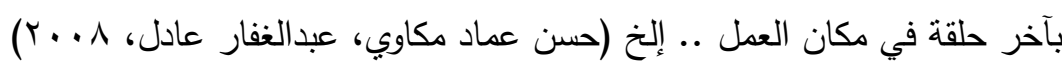
وعلى هذا، فإن الدور الكبير واقع على وسائل الإعلام المرئية والمسموعة والمقروءة؛

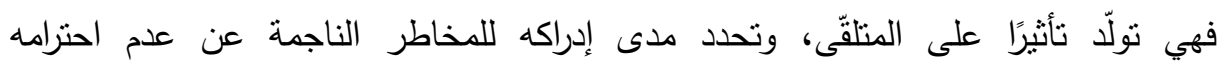
للمنطلبات البيئية وللقوانين التي تكفل الحفاظ عليها، وعدم التعسف في استخدام مواردها؛

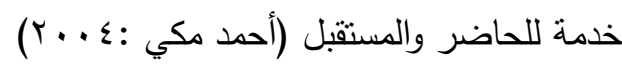
وإلى جانب دور وسائل الإعلام في هذا المجال، تأتي مسئولية الوزارات المعنية، ومنها

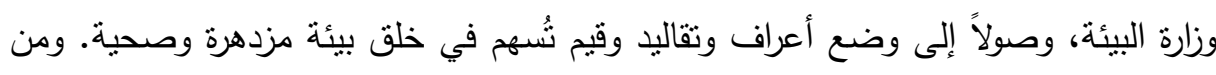

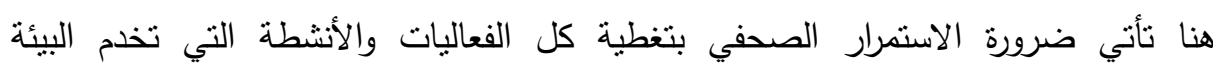

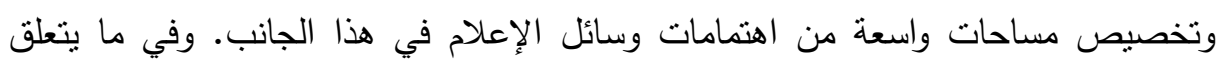

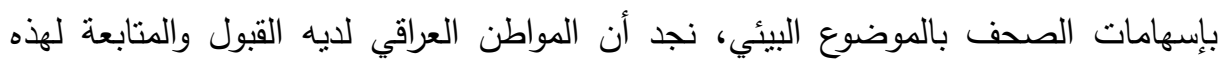
النشاطات والفعاليات التي تتعلق بالبيئة من أجل أن بتعلم ويعرف الكثبر من الأمور البيئية

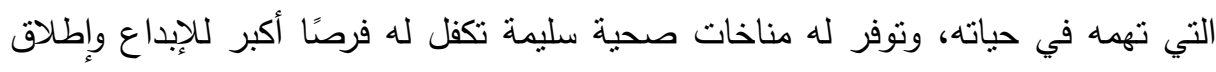
مواهبه؛ خدمة لمجتمعه ووطنه. فالبيئة السليمة والخالية من التلوث عامل مهم في توسيع دائرة النشاط للناس الذين يعيشون في دائرة هذه البيئة والعكس بالعكس.(أحمد مكي ،مرجع السابق).

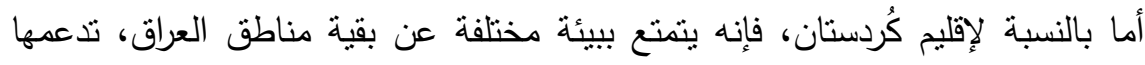
تضاريس الطبيعة، حيث الجبال والوديان والأنهار والغابات الطبيعية. ولكن هذه البيئة معرضة بلئة

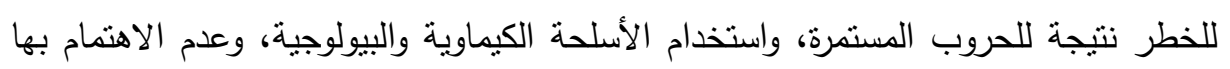


من قبل الحكومات المعنية. بالإضافة إلى تعرض العراق والمنطقة، خلال السنوات الأخيرة،

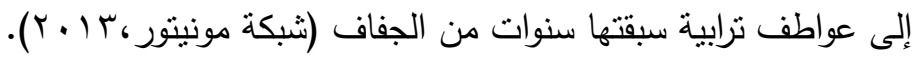

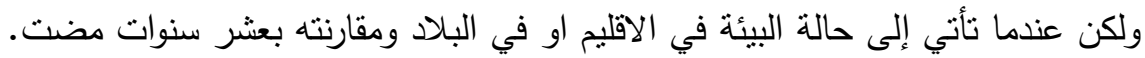

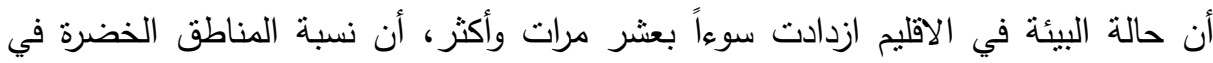
داخل مدينة اريبل،عاصمة اقليم كردستان حسب إحصائية ما قامت به وزارة البئه البئة في الاقليم لا يتجاوز نسبته عن (^, ا\%) في حين يكون حسب المقياس العالمي يجب أن لا يقل نسبته

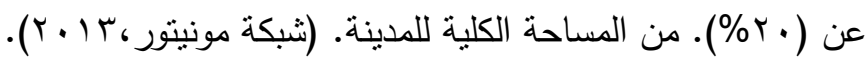

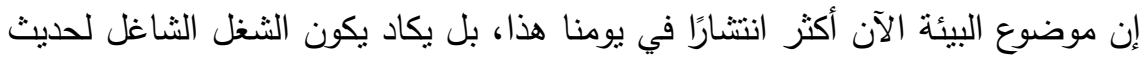
المؤسسات المختلفة، وقد حظى بنصيب وافر في وسائل الإعلام المسموعة والمقروءة والمطبوعة والمرئية والتفاعلية، وأول نشاط أممي رسمي للاهتمام بالبيئة جاء من خلال:

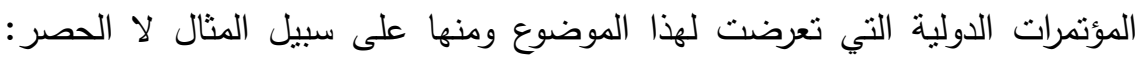
مؤتمر ستوكهولم عام (9YY (م)، ومؤتمر ريوديجانيرو عام (Yr9Y (م) وبروتوكول كيوتو

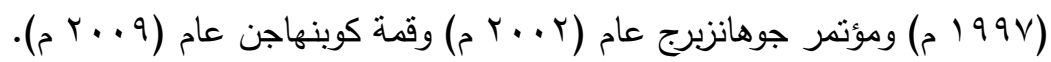
إذن فإن تحسين البيئة والمحافظة عليها أصبحت مسئولية مشتركة على المهن المستوى الداخلي والعالمي، وأدخل التعليم البيئي في المراحل الدراسية، وانتشر الإعلام البيئي، وعملت المنظمات غير الحكومية، ووجهت الأنظار إلى تكاليف إصلاح وحماية البيئة.

\section{And}

قام الباحثون بـإجراء دراسـة استطلاعية علي مجمـوعتين من الاعداد الصحيفة حيث

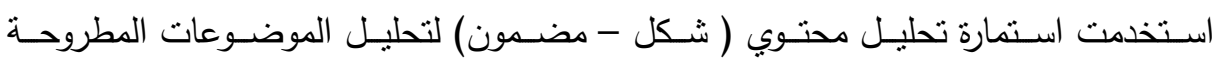

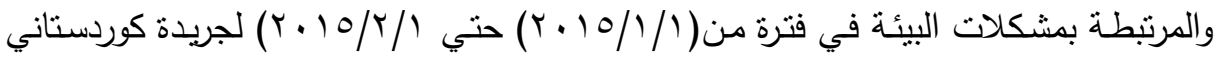
نوي البومية، وجريدة هةولير اليومية فُوجد أن نسبة الموضوعات البيئية الذي تتاولتها جريدة

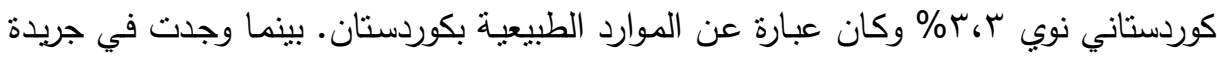

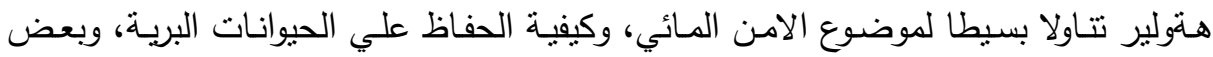

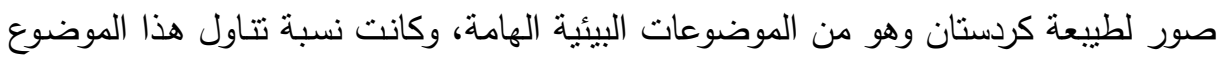

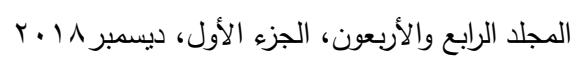


بالجريدة خـلال المدة المطروحة سابقا ؟,ء\%\% \% كذلك تم تطبيق أحد مقاييس التتور علي

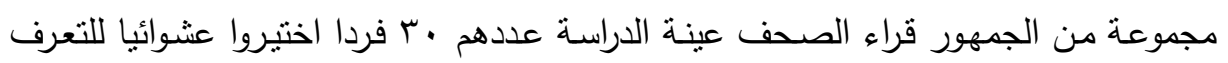
علي مدي تتورهم البيئي وقد اسفرت هذة الدراسـة عن أن نسبة التتور البيئي لدي هؤلاء

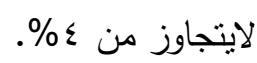

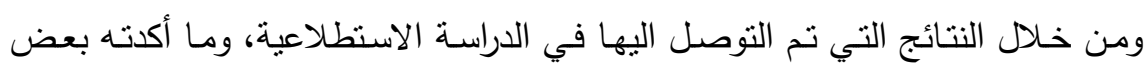

الدراسـات السـابقة، مثنل دراسـة (محسـن محمد امسين قـادر ، 9 . . ب) ودراسـة ( أيسـر خليـل

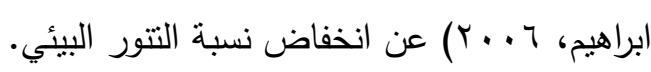
مما حدا بالباحثون القيام بدراسة للتعرف علي دور الصحافة في نتمية التتور البيئي لدي لئي الجمهور بأقليم كردستان العراق.

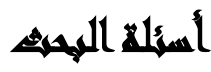

\author{
يحاول البحث الإجابة علي الاسئلة التالية: \\ ا ـ ما القضايا والمشكلات البيئية التي يعاني منها إقليم كُردستان؟ الإنها

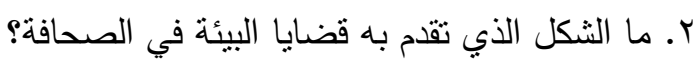

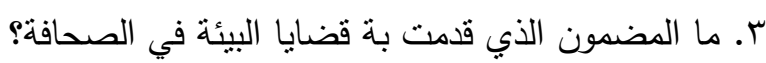

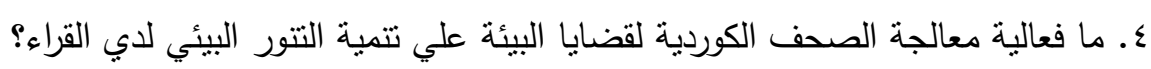

\section{أهسا هـ المهمه}

تهاف الدراسة إلي تحقيق مجموعة من الأهداف يأتي في مقدمتها ما يلي:

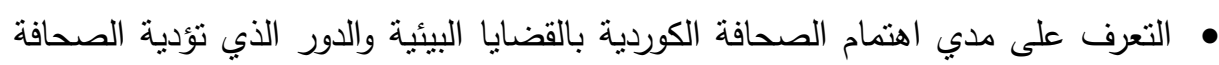
في تتمية النتور البيئي للجمهور في اقليم كوردستان. • التعرف علي أراء القائمين بالاتصال فيما تقدمة الصحافة من معالجة لقضايا البيئة. 


\section{هروضر الهمهث}

يحاول البحث الحالي الإجابة علي الفرض التالي: توجد فروق دلة بين الدرجات التي يحصل عليها القراء من المجموعة التجريبية في مقياس التتور البيئي قبل وبعد قرائته لما جاء بالصحف لصالح التطبيق البعدي، ويتفرع من الفرض الرئيسي الفرضين التاليين:

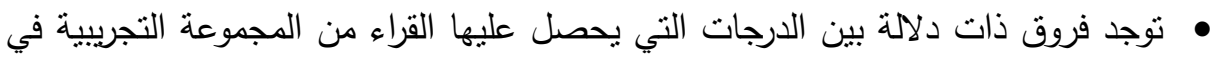
اختبار المعارف البيئية قبل وبعد قراءتهم لما جاء بالصحف لصالح التطبيق البعدي. • توجد فروق ذات دلالة بين الدرجات التي يحصل عليها القراء من المجموعة التجريبية في مقياس الاتجاهات البيئية قبل وبعد قراءتهم لما جاء بالصحف لصالح التطبيق البعدي.

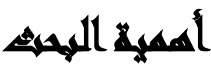

ترجع أهمية البحث إلى عدة أمور، منها: 1. الصحافة من تقديم موضوعات تساعد علي نتمية التتور البيئي للجمهور في إقليم كُوردستان.

r. تقيد القائمون على الهيئة العامة لحماية البيئة وقطاعات من الجمهور في إقليم كُردستان. r. تقديم قائمة بعناصر ومكونات التتوير البيئي، وأدوات بحثية متمثلة في استمارة تحليل

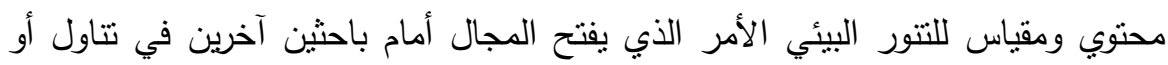
التعرف على المشكلات البيئية ووضع الحلول المناسبة لها.

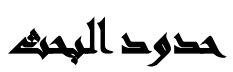

أولاً: حدود مكاتية: الصحف اليومية في إقليم كردستان وقطاعات من الجمهور

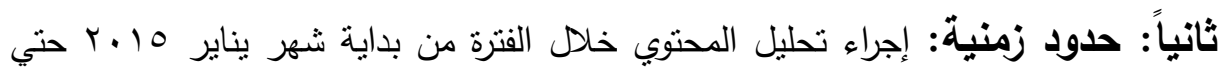

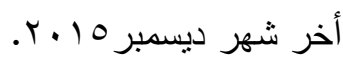
ثالثاً: حدود بشريةة: تحددت بمجموعة من القراء بلغت (·r) فرداً. 


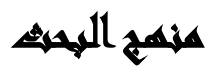

• يستخدم البحث المنهج الوصفي والمنهج شبه النجريبي ويعتمد في إطار هذين المنهجين

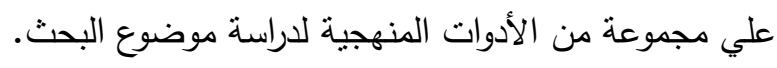

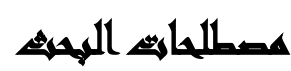

الإعلام البيئي: هو كافة أوجه الأنشطة الاتصالية التي تستهدف تزويد الجمهور بكافة

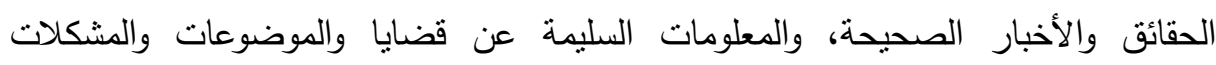

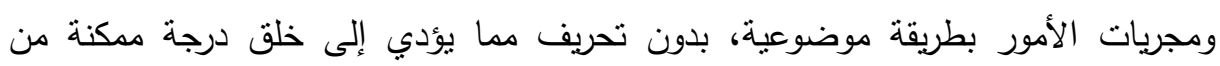

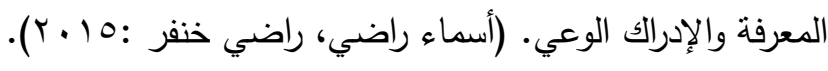

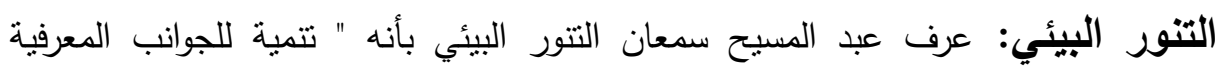

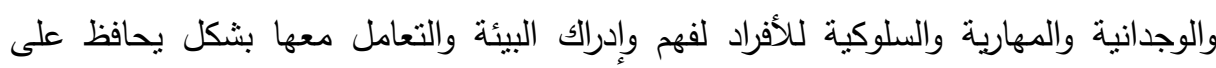

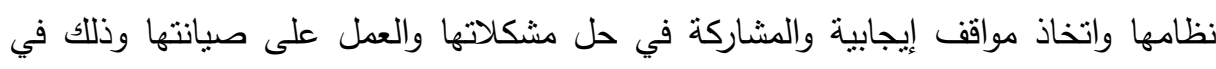
إطار تتمية تتواصل بشكل دائم (عبد المسيح سمعان: ... ب).

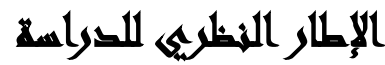

الإعلام البيئي: هو توظيف وسائل الإعلام توظيفا منهجيا من قبل أنخاص مؤهلين بيئيا

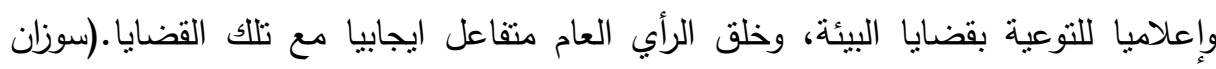

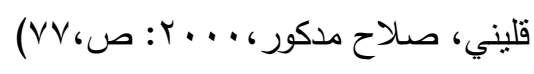

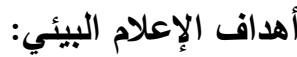
• • نشر الوعي البيئي من خلال أجهزة الإعلام، المقروهة، والمسموعة، والمرئية. • • • الترشيد للتخلص من القمامة والمخلفات بالسلوك الإنساني.

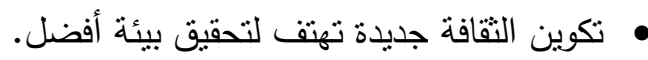

• إنتاج برامج متخصصة وأعمال تلفزيونية حول حماية البيئة من الأخطار التغيرات المناخية

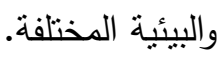
• عرض برامج إرشادية وبرامج توعية مختلفة بالتلفزيون و أماكن تجمع الجماهير والثباب. 430

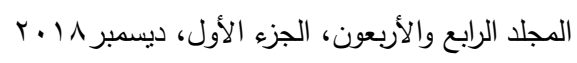


• المساهمة في تعليم الفرد و كيفية التعامل مع البيئة وجعل هذا الوعي سلوكا له.

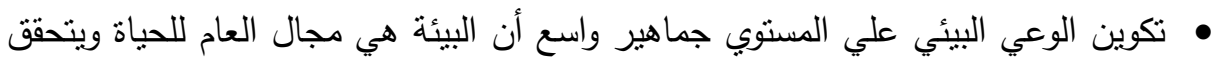
هذا من خلال البرامج والمسلسلات الهادفة والإعلانات المعتمدة علي الرسوم المتحركة.

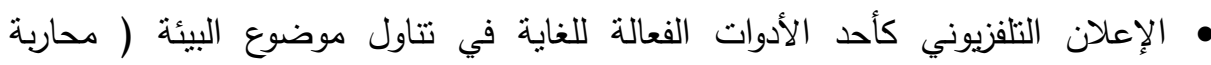

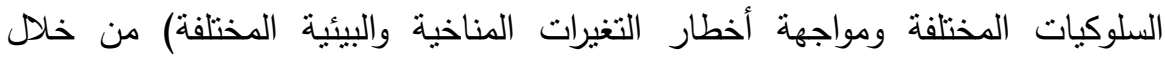
الرسائل الإعلانية التي تدور حول أفكار مختلفة. الصحافة المكتويةة: تُعد الصحافة المكتوبة من أقدم وسائل الإعلام في التاريخ، ويعود لها لإنال الفضل في الحفاظ علي تواصل وتتناقل مختلف المعارف والمعلوم والثقافات بين الأجيال في مختلف مناطق العالم منذ ظهورها قديما، وكونها أول وأقدم وسائل الإعلام أطلاقا، فقد احتلت الصحافة المكتوبة حيزا كبيرا من الاهتمام الجماهيري بها، واستطاعت أن تجد لنفسها مكانة مرموقة في جميع المجمعات. فالدكتور (إبراهيم إمام) يري أن الصحافة هي النشر عن طريق وهن النيق الوسائل المطبوعة دوريا. ( إبراهيم إمام : (99 (1) ). خصائص الصحافة المكتوية: تتميز الصحافة المكتوبة عن باقي وسائل الإعلام في العديد من

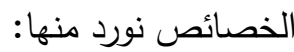
1-تعتبر الجرائد من الوسائل السهلة والسريعة في نقل الرسائل الإعلامية إلى الجمهور . ץ-إن كلمة مطبوعة لها قوة استمرارية أبعد من كلمة منطوقة أو الصورة المرئية لآن القراء

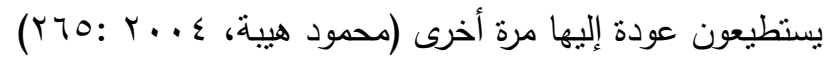
r-المادة إعلامية في الجريدة مكتوبة وملموسة للقارئ وذلك تساعد في إنارة اهتمام القارين بالمضمون. ع-قراءة الجرائد عادة تكمن للقارئ من سيطرة علي ظروف التعرض أكثر من مرة للرسالة،

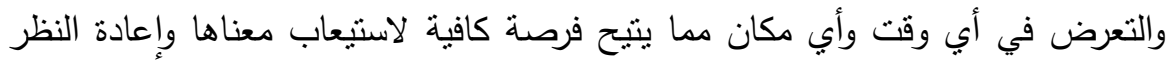

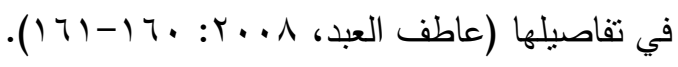

التنور البيئي: هو أحد أهم غايات التربية البيئية وتتمنل في إعداد المواطن المتتور بيئياً وقد شرع (Disiner 1992) في تحديد الدفهوم من خلال دراسته للعلاقة بين التتور البيئي والتربية

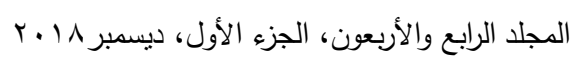


البيئية في حين عرض (David 1974) تصوره عن مفهوم التتور البيئي بأنه بتضمن

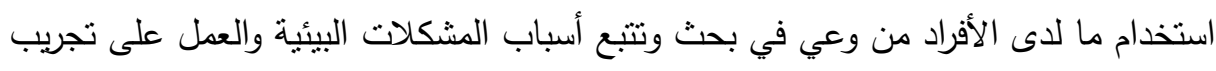

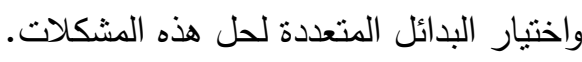

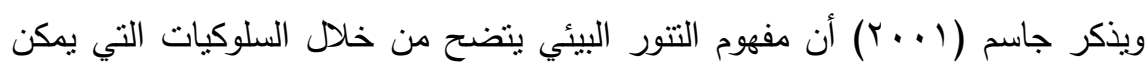

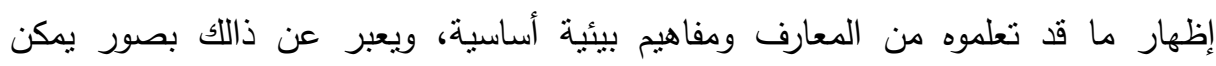
ملاحظتها. من خلال العرض السابق لمفهوم التتور البيئي يتضح انه يتضمن الأتي:

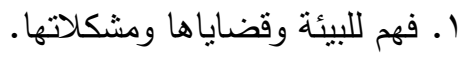

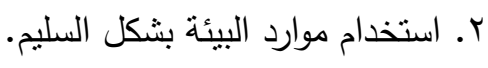
r. إمتالكا اتجاهات ايجابية نحو البيئة.

أهداف التتور البيئي: في ضوء تحديد مفهوم التتور البيئي يمكن تحديد أهداف التتور البيئي في الآتي: 1. أ اكتساب الدكونات المعرفية والانفعالية والسلوكية في البيئة.

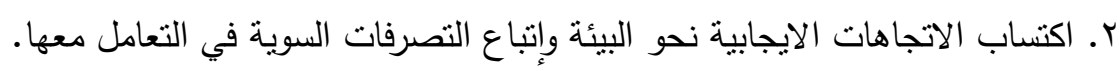
r. الفهم السليم للتفاعلات بين المكونات البيئية.

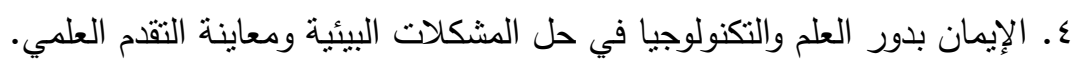

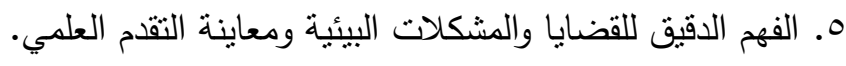

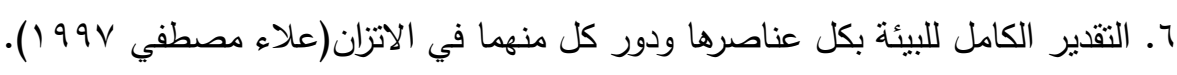

\section{أسوايت وإجراعاهي التراسمة}

أولاً: أدوات الدراسة أولا: إعداد قائمة القضايا البيئية: تم إعداد قائمة بأهم القضايا البيئية في الصحف الكوردية المطبوعة بإقليم كوردستان. 
رجع الباحثون إلى العديد من المصادر لتحديد قائمة القضايا والمشكلات البيئية ذات الأولوية في كوردستان، من هذه المصادر : خبراء في مجال البيئة - أعضاء المجالس المحلية - تقارير هيئة العامة لحماية البيئة.

وتم إعداد قائمة مبائية بالقضايا البيئية: في ضوء مراجعه مصادر أشتقاق قائمة القضايا

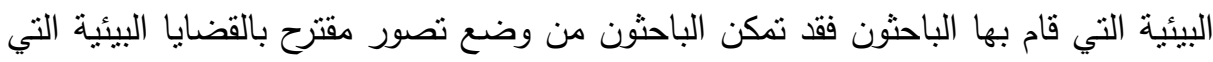

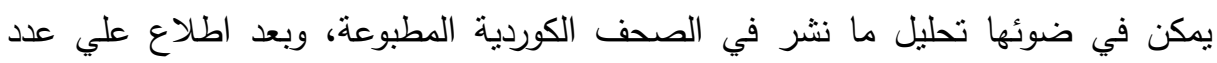

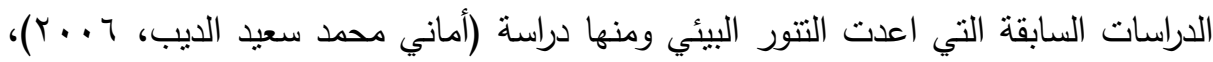

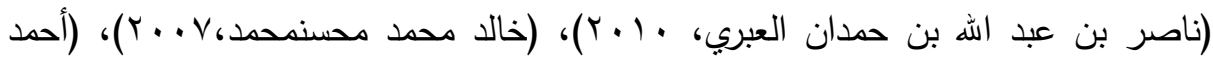

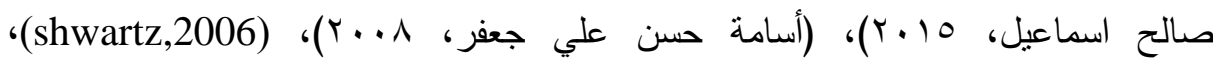

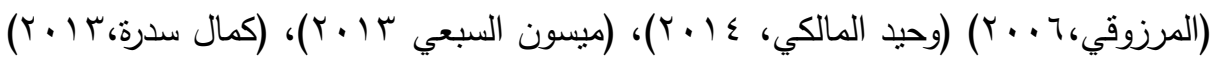
2001 Roper,)

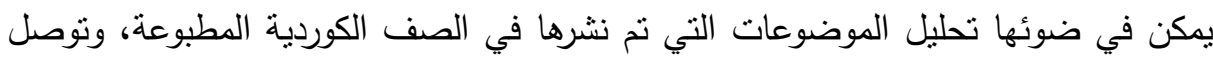
الباحثون الي اعداد قائمة بمشكلات البيئة. ضبط القائمة: للتأكد من أهمية هذه القضايا ومناسبتها للنشر في الصحف الكردية المطبوعة، ووضوح صياغتها، نم عرض القائمة على السادة المحكمين، ذو الخبرة في مجال البيئة والاعلام، وذللك للتعرف على آرائهم من حيث مدى أهية القضايا البيئية.

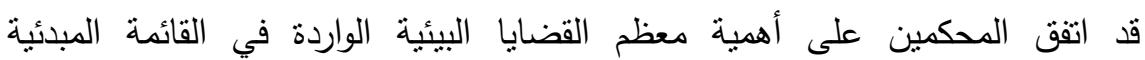
وملائمتها، إلا أن بعض المحكمين طلب تعديل الدلالة اللفظية لبعض القضايا الواردة بالقائمة المبئية المقترحة، وفى ضوء آراء السادة المحكمين تم تعديل وأستبعاد واضافه بعض القضايا. الصورة النهائية لقائمة القضايا البيئية: في ضوه ضوه التعديلات السابقة تحددت القضايا البيئية التي يلزم تحليها في الصحف الكردية المطبوعة عينة الدراسة في صورتها النهائية على النحو 
جدول( (1) : قائمة بأهم القضايا البيئية في إقليم كوردستان

\begin{tabular}{|c|c|c|c|}
\hline المصادر & القضايا الفرعية & القضايا الأساسية & e \\
\hline صناعية & حرق النفايات - عوادم السيائرات - تشغيل المولدات & \multirow{2}{*}{ تلوث الهواء } & \multirow{2}{*}{1} \\
\hline طبيعية & 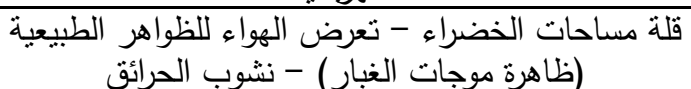 & & \\
\hline صناعية & مصافي نفط الخام - مصافي زيوت سبارات & تلوث التربة & r \\
\hline--- & المستشفيات والعيادات & \multirow{3}{*}{ المخلفات } & \multirow{3}{*}{ r } \\
\hline$\overline{---}$ & مخلفات صلبة (المنازل) & & \\
\hline صناعية & مخلفات صناعية: معامل كسارة الحجر - معامل الزفت & & \\
\hline & إلقاء مخلفات صناعية سائلة - إلقاء مخلفات عضوية & \multirow[t]{2}{*}{ تلوث المياه } & \multirow[t]{2}{*}{$\varepsilon$} \\
\hline & المياه النقيلة والصرف الصحي & & \\
\hline & الصيد الجائر & اختلال التوازن البيئي & 0 \\
\hline
\end{tabular}

ثانياً: إعداد استمارة تحليل المحتوي التي تضمنتها الدراسة : قام الباحثون بالاطلاع علي البئي

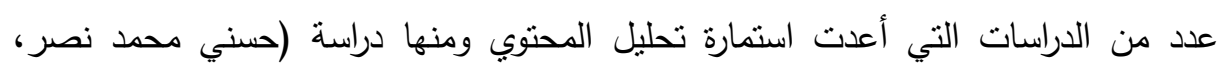

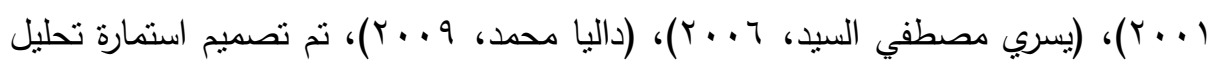

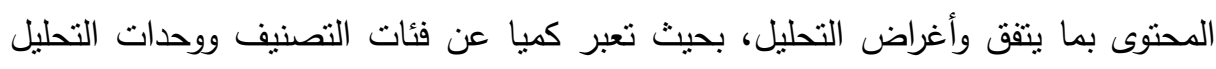

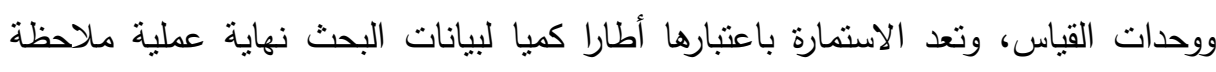

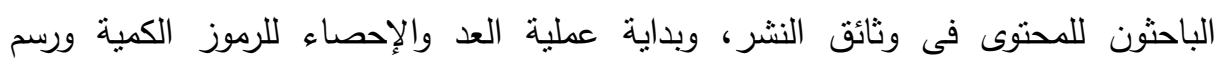

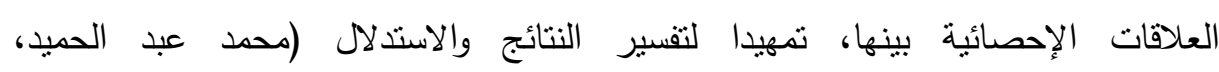

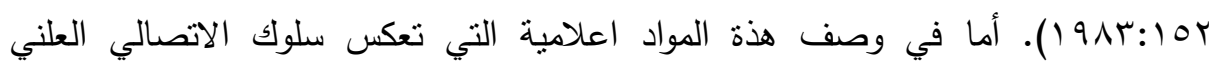

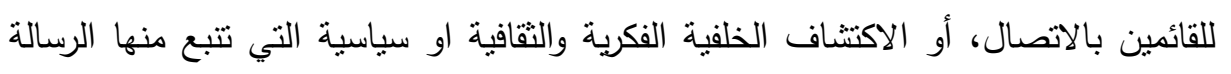

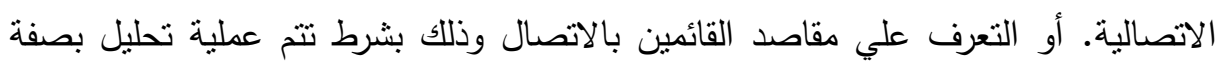

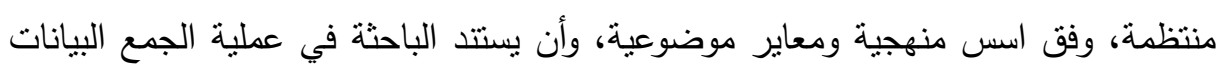

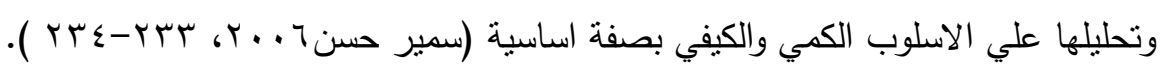
وكما عرف كيرلينجر (kerlinger,1984) تحليل المضمون بأنة، طريقة لدراسة وتحليل

الرسالة الاعلامية بشكل منتظم. 
عرفتة دائرة المعارف الدولية للعلوم الاجتماعية بأنة : احد المناهج المستخدمة في دراسة

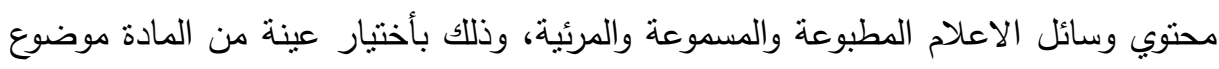

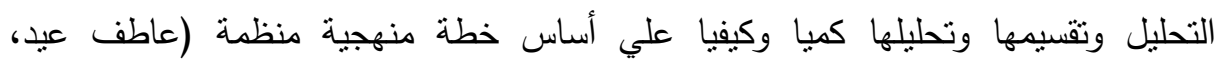
(r.人) (r...r

وقد تم تصميم استمارة تحليل المحتوى (الثكل - المضمون) بناء على تحديد الهدف

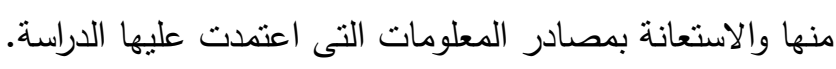

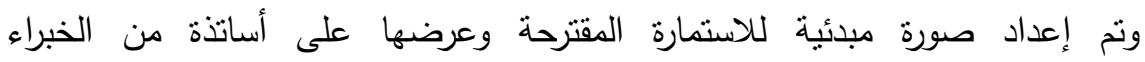
والمتخصصين فى مجال الإعلام والصحافة للاسترشاد بآرائهم وتعديلاتهم وإضافاتهم العلمية دئه

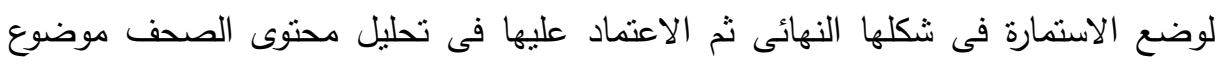

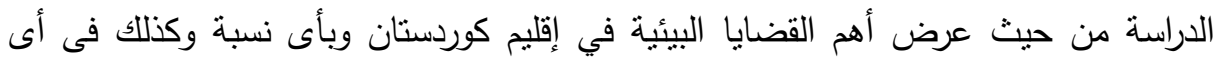
شكل صحفى وذلك كالآتى:

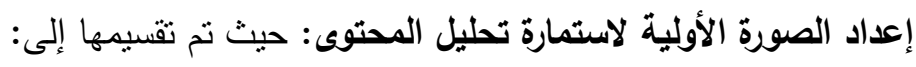

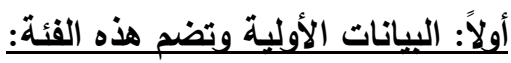
• اسم الصحيفة: يقصد بها اسماء الصحف موضوع الدراسة • • صحف الدراسة وتشمل (صحيفة هنولير وكوردستاني نوي- جريدة هةولير اليومية). • جهة الإصدار : يقصد بها الجهة التى تصدر عنها الصحيفة. • • دورية الصدور : بقصد بها عدد مرات صدور الصحيفة (بومياً). ثانياً: فئات الشكل وتضم ما ليلي:

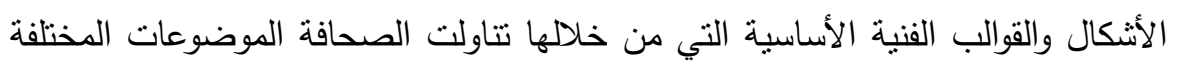

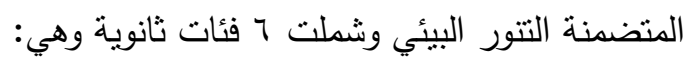
فئات الموقع: ويقصد بها مكان القضايا البيئة في صحف الدراسة، وتقيد في التعرف على لئى مدى الاهتمام بهذه الموضوعات وتتقسم إلى ثلاثة أقسام: • الصفحة الأولى: وتتشر القضايا البيئة في الصفحة الأولي للصحيفة.

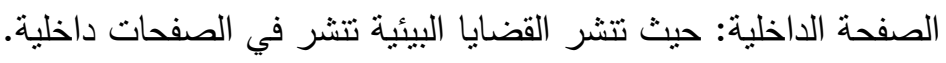

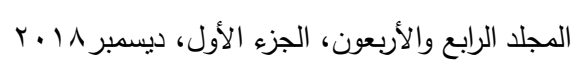


• الصفحة المتخصصة: حيث نتشر القضايا البيئية في الصفحة خاصة بالبيئة، وتأتي أهميته بعد الصفحة الأولى. هكل المادة الصحفية: من حيث الخبر - تحقيق - حديث - مقال - عمود - تقرير كاريكانير

ثالثاً: فئات المضمون وتضم ما بليخ:

• القضايا البيئية: (تلوث الهواء - تلوث التربة - المخلفات - تلوث الماء - اختلال التوازن البئي). • ظهور المشكلة: البيئية نتيجة النشاطات الإنسان، ويجب عرض المعلومات حول الحدث البيئي وتطرق لأسبابه وأثاره ونتائجه. • أسباب المشكلة: ويقصد في هذا النوع من المعالجة عرض الحدث البئئئي، وتحديد أسبابة، والعوامل المؤدية له.

• آثار المشكلة: يقصد به أن ينم عرض الحدث البيئي وتحديد أثاره، ونتائجه المحتملة.

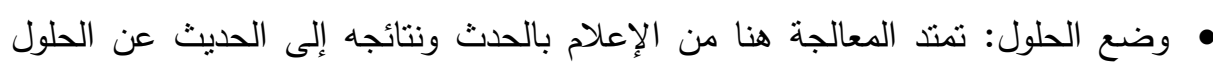

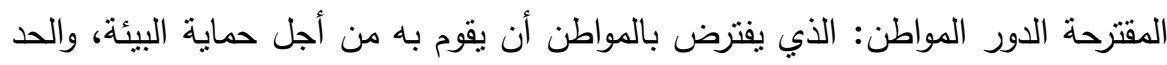

$$
\text { من مشكلاتها وتعديل سلوكه. }
$$

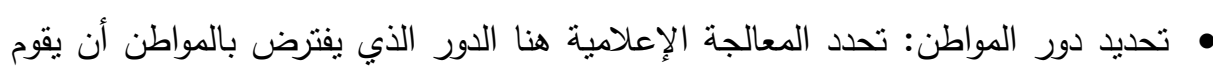

به في حماية البيئة، والحد من مشكلاتها وتوجيهه سلوكه اتجاه البيئة.

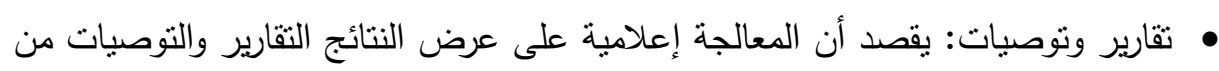
مؤسسة الحماية البيئة والجهات رسمية مسئولة عن البيئة. • تحديد دور الجهات الرسمية: هنا يتم الحديث عن الدور الحكومة أو أي الجهات الرسمية منية الرئة مثل مؤسسة الحماية البيئة وصونها.

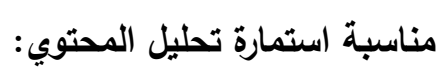
صدق استمارة التحليل: يقصد بالصدق صلاحية الأسلوب أو الآداة لقياس ما هو مراد قياسه

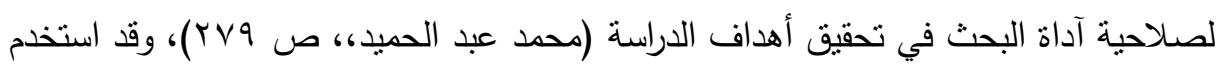
الباحثون صدق المحتوي للنأكد من مناسبة الاستمارة للهدف الذي وضعت من أجله وذلك 
بعرض الاستمارة علي محكمين خبراء في الدراسات الإعلامية، وبعد استعراض آراء المحكمين والتي تبين من خلالها موافقته علي معظم ما جاء بالاستمارة من فئات ووحدات المقياس، تم إجراء بعض التعديلات في استمارة التحليل.

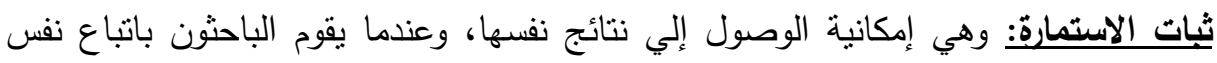

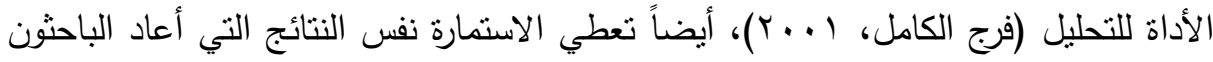

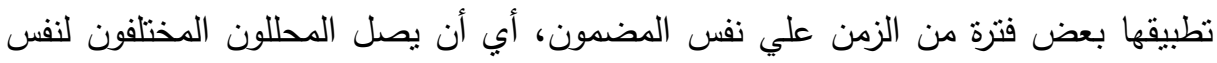
النتائج عند استخدام تلك الاستمارة علي نفس المضمون ويكون بينهم نسبة عالية من الاتفاق

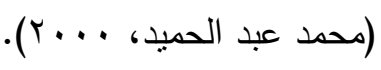

وتحقيقاً لذلك قام الباحثون بتحليل عينة من الصحف عينة الدراسة في الفترة من

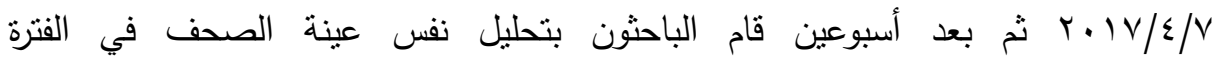

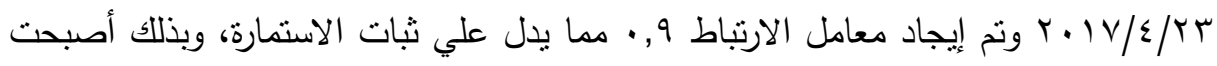
الاستمارة في صورتها النهائية. ثالثاً: إعداد مقياس التنور البيئي: قام الباحثنون بإعداد مقياس التتور البيئي التي شملت:

$$
\text { • اختبار المعارف البيئية. }
$$

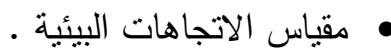

يهدف المقياس إلي قياس التتور البيئي لدي قطاعات من الجمهور في أقليم كوردستان

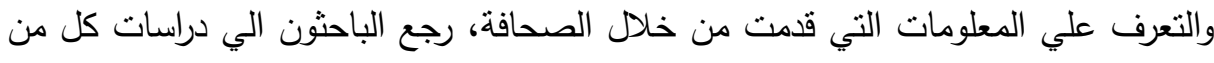

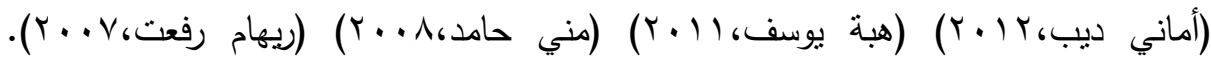

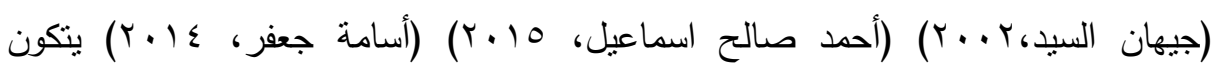
المقياس في صورتة المبدئية 0 ؛ سؤالا.

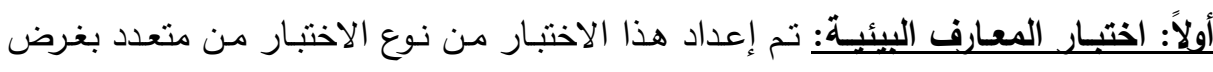

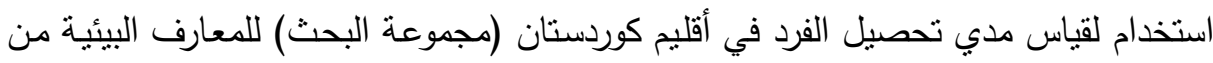
خلال متابعتهم للجرائيد اليومية في ضوء أبعاد نتمية التتور البيئي ـ وقد اتبع في بناء الاختبار 
• الـهوف من الاختبار: يهدف الاختبار الى التعرف علي المعارف البيئية لدي عينة الدراسة.

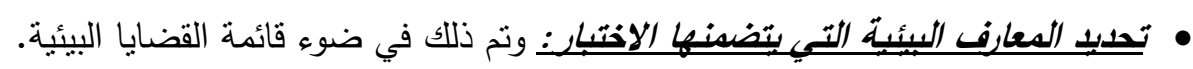
• وصف الاختبار: تكون الاختبار من (Y0) سؤالا، يتضمن كل سؤال على اجابات فرعية يستجيب لها المبحوث. • ضبط اختبار المعارف المبئية: نم ضبط المقياس من خلال ما يلي: • مدق الاختبر:

أ- الإجراء الأول صدق المحكمين: للتحقق من صدق الاختبار نم عرضه على المحكمين

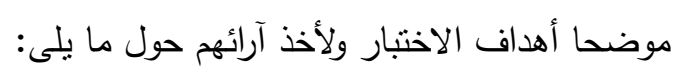

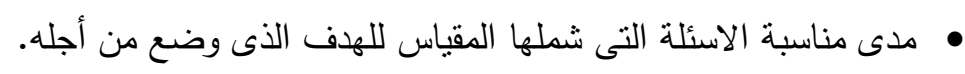

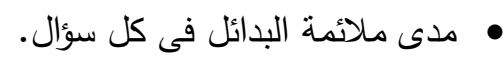
• • • ملامة صياغة الأسئلة والبدائل وملائمتها. وعند استعراض آراء المحكمين، وجد اتفاق كبير فى آرائهم حول سلامة الأسئلة

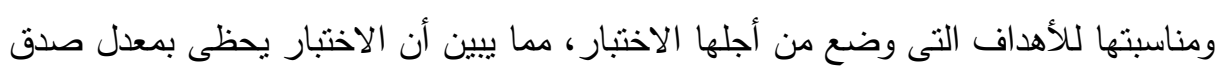
مرتفع. ب- الاجراء الثانى حساب صدق الاتساق الداخلي: من خلال معامل ارتباط بيرسون لبنود اختبار المعارف البيئية وذلك على النحو التالي: جدول(r): صدق الاتساق الداخلي لاختبار المعارف البيئية

\begin{tabular}{|c|c|}
\hline معامل ارتباط بيزسون & آبعاد اختبار المعارف البيئية \\
\hline., 974 & تلوث الهواء \\
\hline., 990 & تلوث التربة \\
\hline$\cdot, 9 \vee 0$ & المخلفات \\
\hline$\cdot, 9 \vee \wedge$ & تلوث المياه \\
\hline$\cdot, 9 \wedge 1$ & اختلال التوازن البي \\
\hline
\end{tabular}

يتضح من الجدول السابق لصدق الاتساق الداخلي لأبعاد الاختبار أن معاملات الإرتباط

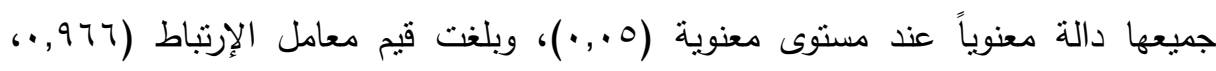

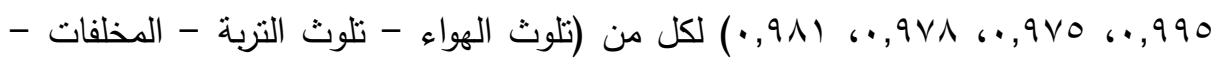


تلوث المياه - اختلال التوازن البيئي) على التوالي مما يؤكد على صدق الاتساق الداخلي لأبعاد الاختبار وصلاحيته للتطبيق.

مما سبق تحقق الباحثون من أن الاختبار يتسم بدرجة صدق عالية تجعله صالح للنطبيق. • ثبات الاختبار: تم استخدام اختبار (ألفا كرونباخ): للتحقق من ثبات المقياس لإمكانبة الاعتماد على نتائج الاختبار باستخدام معادلة ألفا كرونباخ (CronbachAlpha)، ويوضح الجدول الثالي معاملات الثبات الناتجة باستخدام هذه المعادلة. جدول(ץ): ثبات اختبار الدعارف البيئية

\begin{tabular}{|c|c|c|}
\hline قيمة ألفا & عدد العبارات & آبعاد اختبار المعارف البيئية \\
\hline$\cdot, 9 \vee r$ & $\bar{V}$ & تلوث الهواء \\
\hline$\cdot, 9 \vee$. & 7 & تلوث التربة \\
\hline$\cdot, \Lambda \cdot V$ & $\bar{Y}$ & المخلفات \\
\hline$\cdot, 9 \pi \xi$ & $\varepsilon$ & تلوث المياه \\
\hline$\cdot, 9 \leqslant 7$ & $\varepsilon$ & اختلال التوازن البيائ \\
\hline$\cdot, 99$ & TM & الكلية لاختبار المعارف البيئية \\
\hline
\end{tabular}

يتضح من الجدول السابق أن قيم معاملات الثبات جميعها قيم مرتفعة حيث بلغت قيم

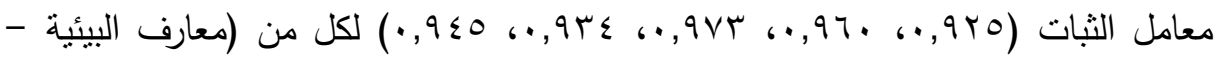
نوعية الهواء - نوعية التربة - نوعية المياه - اختلال التوازن البيئي) على التوالي، وكانت

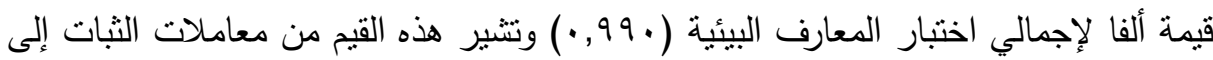
صلاحية العبارات وإمكانية الاعتماد على نتائجها والوثوق بها.

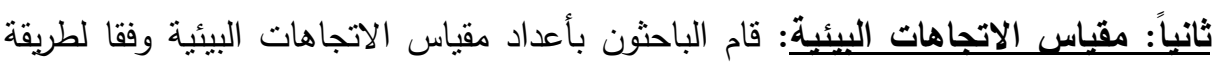
كراثول (Krathwohl,DavidR.e al 1964:176-184). حيث يري كارانول أن المكونات الجانب الوجداني أو انفعالي للفرد تقوم علي أساس مدي قوة ما

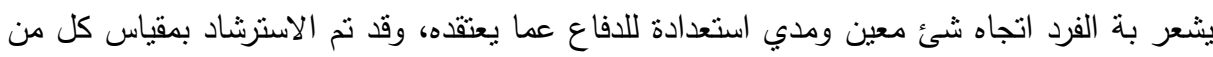

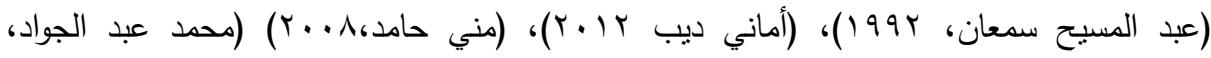

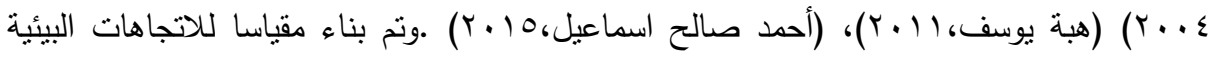
علي شكل مواقف سلوكية وقد شملت عملية إعداد المقياس الخطوات التالية:

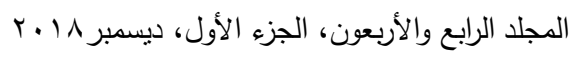


الثيف من المقياس: يهدف المقياس الى قياس الاتجاهات البيئية علي شكل مواقف للأفراد نحو مشكلات البيئية في أقليم كوردستان في ضوء متابعتهم للصحف المحلية في ضوف البهائ البعاد التتور البيئي.

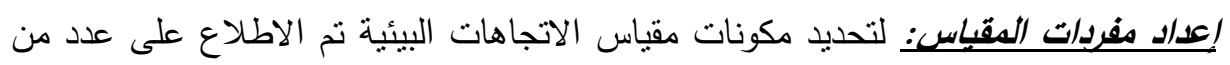
الكتابات والدراسات والبحوث السابقة التي تتعلق بمقياس الاتجاهات البيئية مثل دراسة ( أسامة التانة

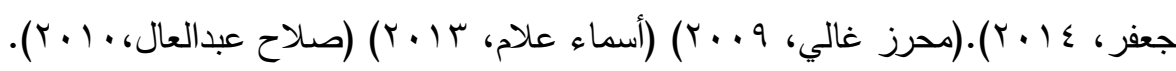

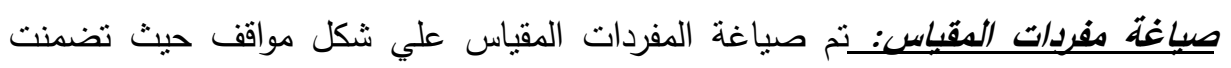
المفردة مقدمة تمنل موقفا ويلي المقدمة ثلات استجابات تمنل تدرجا لاستجابات الفرد تجاة

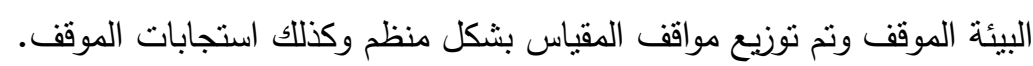
نظام تقدير الارجات نم حساب مايلي: • الأولي تدل علي الاتجاه الايجابي (درجتان). • • الثانية تدل علي الوعي (درجة واحدة). • م الثالثة تدل علي الاتجاه السلبي (صفر ).

وصف المقياس: إنها اشتملت علي عناصر التتور البيئي ومكونتها المختلفة وكذلك طريقة تقديم الاختبار وأسس وبناء التي اعتمدت عليها هذه المقياس وجميعا كانت مقدمة للجمهور القراء.

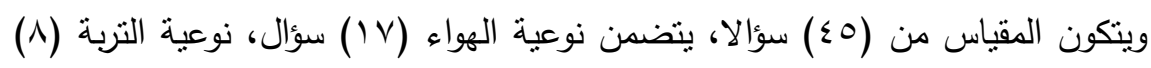

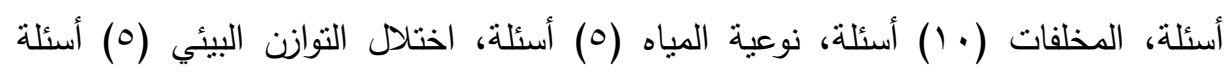
يستجيب لها المبحوث. الصوية المبلئية للمقيسف تم بناء المقياس بمراعاة الأسس التي سبق الاثارة إليها وتتكون من: ضبط المقياس: نم ضبط المقياس كالتالي: صدق المقباس: أ- الإجراء الأول صدق المحكمين: للتحقق من صدق المقياس نم عرضه على المحكمين

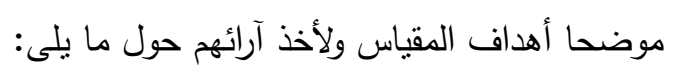

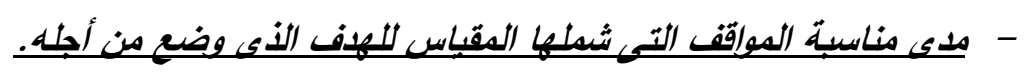
- ملى ملائمة البلائل فحى كل موقف. 
- سلامة صبياغة المواقف والثبائل وملائمتها: وعند استعراض آراء المحكمين، وجد اتفاق كبير فى آرائهم حول سلامة المواقف ومناسبتها للأهداف التى وضع من أجلها المقياس، مما

$$
\text { يبين أن المقياس يحظى بمعدل صدق مرتفع. }
$$

ب- الاجراء الثانسى حساب صدق الاتساق الداظلي: من خلال معامل ارتباط بيرسون لبنود

$$
\text { اختبار المعارف البيئية وذللك على النحو التالي: }
$$

تم حساب معاملات ارتباط كل بعد من أبعاد المقياس بالدرجة الكلية للمقياس والتي التي

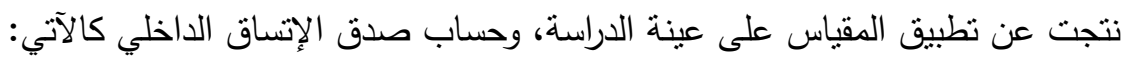

\begin{tabular}{|c|c|}
\hline معامل ارتباط بيرسون & ابعاد مقياس الاتجاهات البيئيةً \\
\hline$\cdot, 991$ & تلوث الهواء \\
\hline$\cdot, 9 \wedge \mathrm{V}$ & تلوث التربة \\
\hline$\cdot, 991$ & المخلفات \\
\hline$\cdot, 97$. & تلوث المياه \\
\hline$\cdot, 9 \times 1$ & اختلال التوازن البي \\
\hline
\end{tabular}
جدول(؛) : صدق الاتساق الداخلي لمقياس الاتجاهات البيئية

يتضح من الجدول السابق لصدق الاتساق الداخلي لأبعاد المقياس أن معاملات الإرتباط

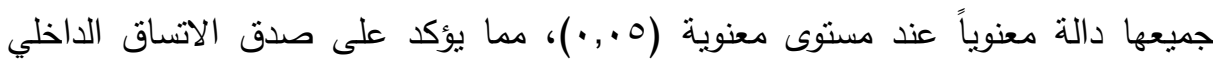
لأبعاد المقياس وصلاحيتها للتطبيق. ثبات الاختبار : نم استخدام اختبار (ألفا كرونباخ):

\begin{tabular}{|c|c|c|}
\hline قيمة آلفا & عدد العبارات & آبعاد مقياس الاتجاهات البيئية \\
\hline$\cdot, 9 \vee \leqslant$ & 1. & تلوث الهواء \\
\hline$\cdot, \wedge \vee q$ & $\mu$ & ت ل تلوث التربة \\
\hline$\cdot, 9 \leqslant \Lambda$ & 0 & 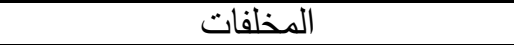 \\
\hline$\cdot, \wedge 07$ & Y & تل ملوث المياه \\
\hline$\cdot, 9 \leqslant 9$ & $\bar{r}$ & اختلال التوازن البيأ \\
\hline$\cdot, 9 \wedge 9$ & TY & الدرجة الكلية لمقياس الاتجاهات البيائية \\
\hline
\end{tabular}
جدول(•): ثبات مقياس الاتجاهات البيئية

يتضح من الجدول السابق أن قيم معاملات الثبات جميعها قيم مرتفعة حيث بلغت قيم

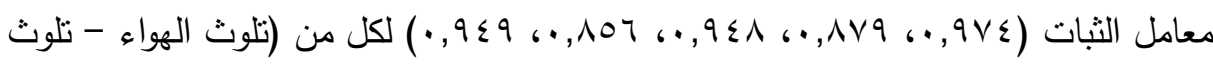

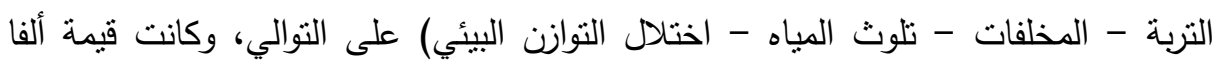

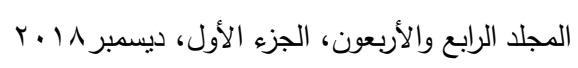


لإجمالي مقياس الاتجاهات البيئية (919,، ·) وتتشير هذه القيم من معاملات الثبات إلى

صلاحية العبارات وإمكانية الاعتماد على نتائجها والوثوق بهات الأنهات

حيث أصبح المقياس في صورته النهائية.

إجراءات التطبيق:

1-عينة التحليل للصحف بلغت عدد صحيفتين ( صحيفة هةولير عدد r.r صحيفة،

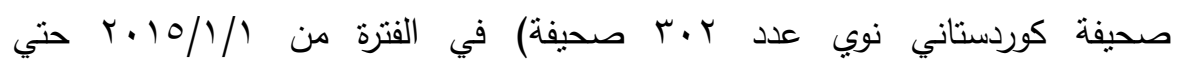
$r \cdot 10 / 1 Y / T$

r-بلغت مجموعة الدراسة (•r ) مارئاً.

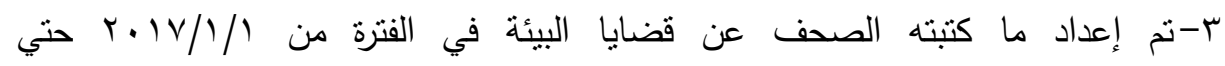
$r \cdot \mid V / T / K / T$

ع-تم تطبيق اختبار المعارف البيئية ومقياس الاتجاهات البيئية علي عينة الدراسة في

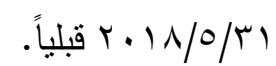

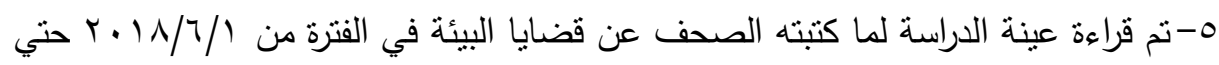

$$
r \cdot 11 / \tau / r \text {. }
$$

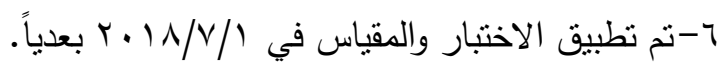
V- آنم معالجة النتائج احصائياً.

\section{Ansillis}

\section{أولاً: النتائج المتعلقة بتحليل المحتوي}

أ- بالنسبة لمدي الاهتمام بقضايا البيئة: بوضح الجدول التالي نكرارات القضايا البيئية لصحيفتي الدراسة (هة ولير - كوردستاني نوي) خلال فترة الدراسة.

جدول(؟): اختبار كاץ لتوضيح الفروق بين صحيفتي الدراسة (هة ولير - كوردستاني نوي) لمدي اهتمام صحف الدراسة لقضايا البيئة

\begin{tabular}{|c|c|c|c|c|}
\hline الالالة & SاY & $\%$ & ك & الصحيفة \\
\hline \multirow{2}{*}{$\cdot, 0$} & \multirow{2}{*}{$\cdot, \Gamma q \wedge$} & $T 1.0$ & 70 & هة ولير \\
\hline & & $19, Y$ & 01 & كوردستانى نوي \\
\hline
\end{tabular}

442

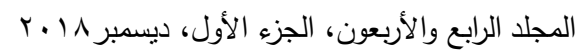


يتضح من بيانات الجدول السابق:

- بلغت عدد المواد الصحفية التي تتاولت القضايا البيئية محل الدراسة في صحف (هفولير

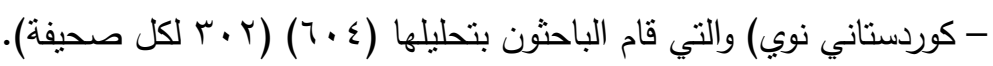

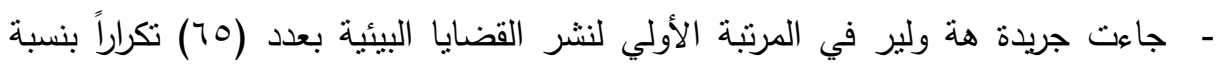
(\% 1,0) من إجمالي الأعداد محل الدراسة، ثم جاءت جريدة كوردستاني نوي في المرنبة

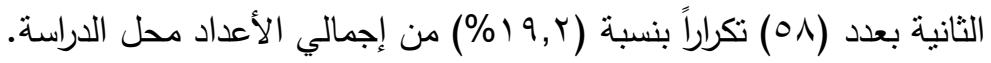

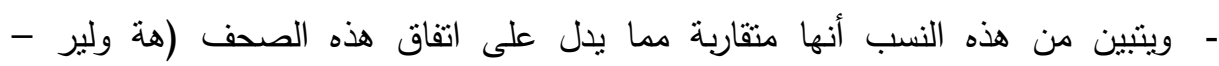
كوردستاني نوي) في الاهتمام بالقضايا البيئية محل الدراسة. جدول(V): إجمالي عدد القضايا البيئية لصحيفتي هنولير وكوردستاني نوي لابيا

\begin{tabular}{|c|c|c|c|c|c|}
\hline النسبة \% & كوردستاني نويفة & النسبة \% & هةولَيفة & القضية & م \\
\hline$\% \vee, 9$ & $r \varepsilon$ & $\%, \Gamma, 0$ & ह1 & تلوث الهواء & 1 \\
\hline$\% r, r$ & 1. & $\% r$ & 9 & تلوث التربة & $r$ \\
\hline$\% 1$ & $\mu$ & $\% \Upsilon, r$ & $\bar{V}$ & المخلفات & $r$ \\
\hline$\% r$ & 9 & $\% \cdot, V$ & Y & تلوث المياه & $\varepsilon$ \\
\hline$\% \varepsilon$ & IT & $\% r$ & 7 & اختلال التوازن البيئي & 0 \\
\hline $19, Y$ & 01 & $Y 1.0$ & 70 & الإجمالي & \\
\hline
\end{tabular}

يتضح من بيانات الجدول السابق: نسب الاهتمام بالقضايا البيئية كان ضيئلاً في الجريدتين.

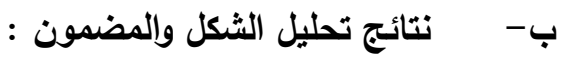


جدول(^): اختبار كاب لتوضيح الفروق بين صحيفتي هةولير وكوردسناني نوي لتحليل الثكل

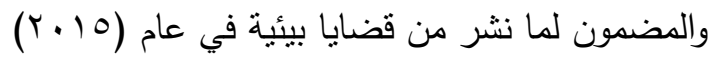

\begin{tabular}{|c|c|c|c|c|c|c|}
\hline الالالة & كاr & كورئنستى & هةوليز & فئات الشكل & \multicolumn{2}{|c|}{ الجريدة } \\
\hline-- & -- & -- & -- & الصفحة الاولي & \multirow{3}{*}{ الموقع } & \multirow{3}{*}{ موقع نشر } \\
\hline$\cdot, \cdots 1$ & rV, & 01 & -- & الصفحة الداخلية & & \\
\hline$\cdot, \cdots 1$ & $7 r, \cdot 71$ & -- & 70 & متخصصحة الصفحة & & \\
\hline$\cdot, \cdot \Gamma$ & $7,9 \cdot 9$ & TA & Y7 & صور & \multicolumn{2}{|c|}{ الصور والرسومات } \\
\hline$\cdot, 1$ & $r, I \wedge Y$ & rq & TV & التكرار & \multirow{2}{*}{ الخبر } & \multirow{14}{*}{ شكل المادة } \\
\hline $0, \Lambda Y$. & $7, V$ TO & 00 & T/7 اسم & المساحة & & \\
\hline$\cdot, r$ & $1, \cdots$ & 1 & $r$ & التكرار & \multirow{2}{*}{ تحقيق } & \\
\hline-- & -- & 0 & ) • & المساحة & & \\
\hline $1, \cdot$ & $\cdot, \cdots$ & 1 & $\cdot$ & التكرار & \multirow{2}{*}{ حديثث } & \\
\hline-- & -- & סاسم & $\cdot$ & المساحةٌ & & \\
\hline$\cdot, \cdots 0$ & $\Lambda, \cdot Y Y$ & $1 \pi$ & Tr & التكرار & \multirow{2}{*}{ مقال } & \\
\hline-- & -- & • • • & 1 & المساحة & & \\
\hline-- & -- & $\cdot$ & $\cdot$ & التكرار & \multirow[b]{2}{*}{ عمود } & \\
\hline-- & -- & $\cdot$ & $\cdot$ & المساحة & & \\
\hline$\cdot, 0$ & $\cdot, 0 \ldots$ & 0 & $T$ & التنكرار & \multirow{2}{*}{ تقرير } & \\
\hline-- & -- & ل ·. (سم & ل عسم & المساحةُ & & \\
\hline-- & -- & $\cdot$ & $\cdot$ & التكرار & \multirow{2}{*}{ كاريكاتير } & \\
\hline-- & -- & . & . & المساحة & & \\
\hline$\cdot, 7$ & $\cdot, Y T Y$ & $1 \cdot$ & $\Lambda$ & ظهور المشكلة & \multirow{7}{*}{\multicolumn{2}{|c|}{ المتضبمنة الأبعاد }} \\
\hline$\cdot, Y$ & $1, \wedge \cdots$ & V & $T$ & اسباب المشكلة & & \\
\hline $1, \cdot$ & $\cdot, \cdots$ & Tr & Tr & أنار المشكلة & & \\
\hline$\cdot, \Gamma$ & 1,19 & $\Lambda$ & $T \pi$ & وضع الحلول & & \\
\hline$\cdot, \cdot r$ & $r, 19$. & $\wedge$ & $1 \varepsilon$ & تحديد دون & & \\
\hline $1, \cdot$ & $\cdot, \cdots$ & 1 & $\cdot$ & تقارير وتوصيات & & \\
\hline$\cdot, .9$ & $r, \wedge \wedge r$ & ir & 0 & الجهاتث الرسمية دورية & & \\
\hline$\cdot, 0$ & $\cdot, 0 \ldots$ & $\Gamma$ & 0 & بذون مصدر & \multirow{5}{*}{\multicolumn{2}{|c|}{ مصادر المادة الصحفية }} \\
\hline$\cdot, 1$ & I, I & rq & ro & والقو المحلية والَّالمباء & & \\
\hline$\cdot, 1$ & T,77V & 0 & $\cdot$ & دراجع علمية & & \\
\hline$\cdot, 7$ & س & ir & 10 & ومتخصبراء خون & & \\
\hline-- & -- & $1 \cdot$ & $1 \cdot$ & مسئولون & & \\
\hline$\cdot, \wedge$ & $\cdot, .70$ & r. & r t a & الصحفيل & \multirow{2}{*}{\multicolumn{2}{|c|}{ كاتب الموضوع }} \\
\hline$\cdot, 0$ & $\cdot, \Sigma) \cdot$ & T人 & TL & المحرر & & \\
\hline
\end{tabular}


- بالنسبة لفئة موقع نشر المادة: يوضح الجدول السابق ان موقع نشر المادة في صحيفة

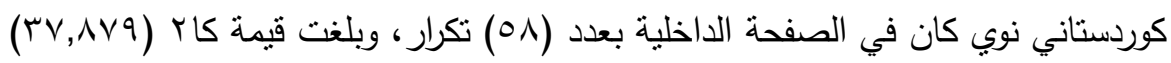

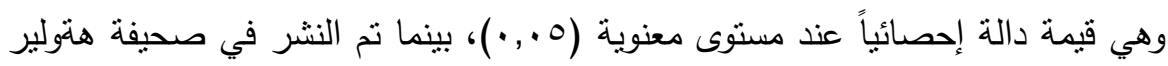

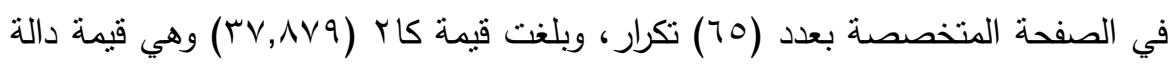
إحصائياً عند مستوى معنوية (0. (•) ).

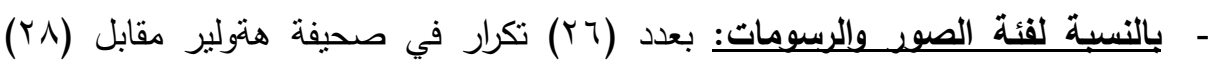

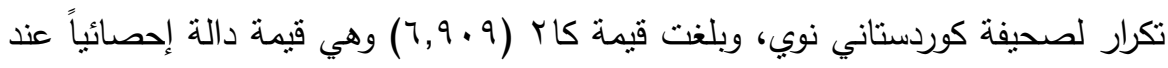
مستوى معنوية (0. (·) ).

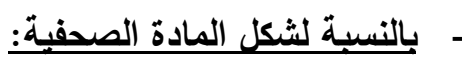

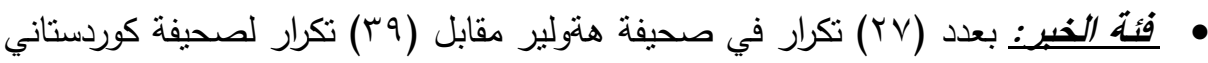

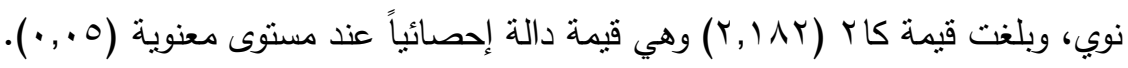
• فئة تحقيق: بعدد (r) تكرارات في صحيفة هنولير مقابل (1) تكرار لصحيفة كوردسناني نوي، وبلغت قيمة كاr (., (1) وهي قيمة غير دالة إحصائياً عند مستوى معنوية $\cdot(\cdot, \cdot 0)$ • فئة حلبث: بعدد (1) تكرار لصحيفة كوردستاني نوي، وبلغت قيمة كاץ ( ( ., •) وهي قيمة غير دالة إحصائياً عند مستوى معنوية (1. . . •).

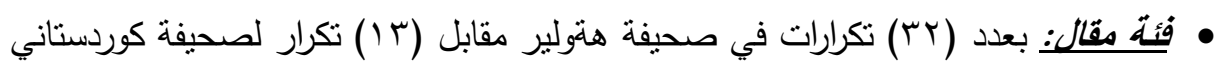

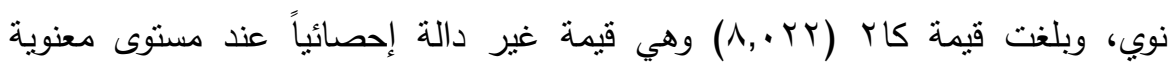
$\cdot(\cdot, \cdot 0)$

• فئة تقريز: بعدد (r) تكرارات في صحيفة هةولير مقابل (0) تكرار لصحيفة كوردستاني

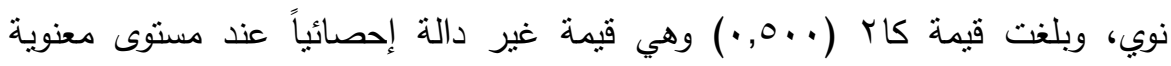
$\cdot(\cdot, \cdot 0)$ 
- مالنسبة للأبعاد المتضمنة:

• فئة ظهور المشكلة: بعدد (^) تكرارات في صحيفة هتولير مقابل (• ( ) تكرارات لصحيفة

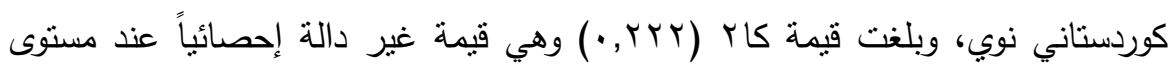

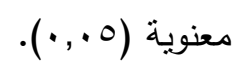

• فئة أسباب المشكلة: بعدد (T) (1) تكرار في صحيفة هةولير مقابل (^) تكرارات لصحيفة

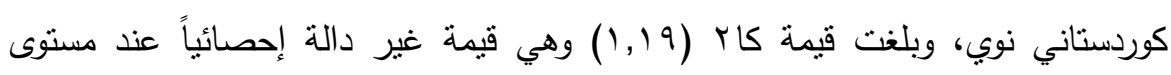
معنوية (0. (·) ).

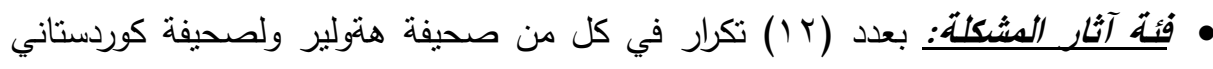

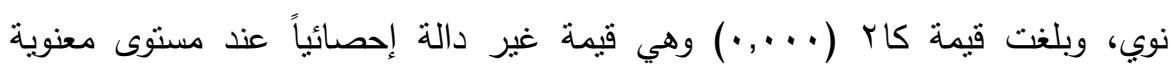
$\cdot(\cdot, \cdot 0)$

• فئة تقارير وتوصبيت: بعدد نكرار واحد لصحيفة كوردناني نوي، وبلغت قيمة كاب

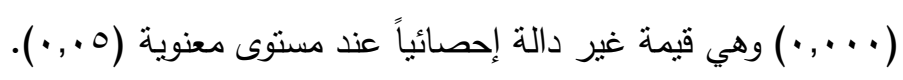
- بالنسبة لفئة تحدبي دور الجهات الرسمبة: بعدد (0) تكرارات في صحيفة هنولير مقابل

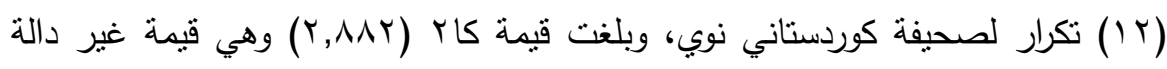
إحصائياً عند مستوى معنوية (0. . . •).

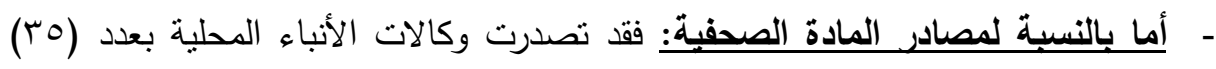

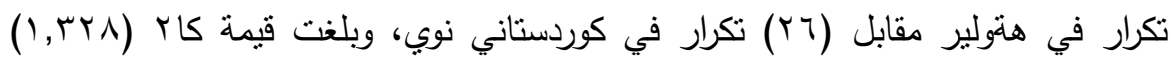

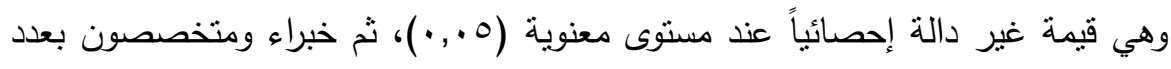

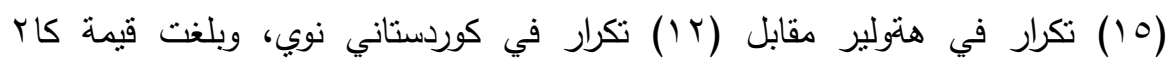

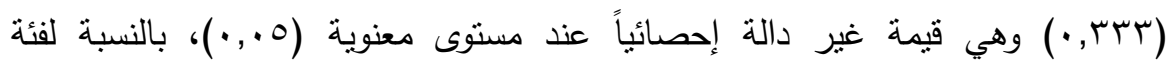

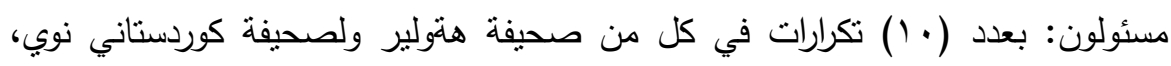

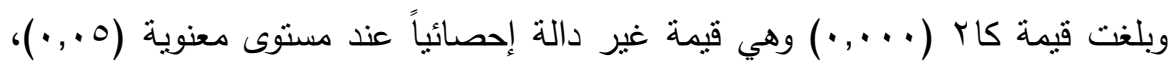

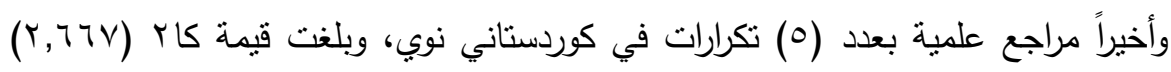

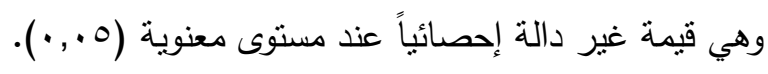


- اما بالنسبة لكاتب الموضوع: الصحفى/مراسل بعدد (rr) تكرار في هةولير وعدد (r^) تكرار في كوردستاني نوي، وبلغت قيمة كاب (• (اء ·•) وهي قيمة غير دالة إحصائياً عند

$$
\text { مستوى معنوية (0., , ). }
$$

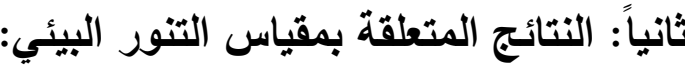

أولاً: نتائج تطبيق اختبار المعارف البيئية

جدول(9): اختبار (ت) (t-test) لحساب الفروق بين منوسط درجات النطبيق القبلي ومتوسط درجات التطبيق البعدي على اختبار المعارف البيئية

\begin{tabular}{|c|c|c|c|c|c|c|c|}
\hline \multirow{2}{*}{ الدستوي } & \multirow{2}{*}{ قتيمة } & \multicolumn{2}{|c|}{ 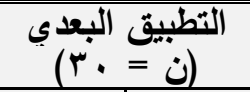 } & \multicolumn{2}{|c|}{ التطبيق القبلى } & \multirow{2}{*}{ الالكلية } & \multirow{2}{*}{ أبعاد الاختبار } \\
\hline & & $\varepsilon$ & r & $\varepsilon$ & p & & \\
\hline دال & $9, Y_{0}$ & 1.91 & $0, Y$. & $1, Y T$ & $r_{6} \| 11$ & $\bar{V}$ & تلوث الهواء \\
\hline غير دال & $\cdot 6 \cdot 11$ & $1, \Delta \mu$ & r.0T & $1 . V A$ & $\left.r_{6}\right)$. & 7 & تلوث التربة \\
\hline غير دال & $\cdot 6 \cdots$ & .694. & $1, \pi$. & $.6 \wedge \wedge$ & $1, \pi$. & $r$ & المخلفات \\
\hline غير دال & $.6 \cdots 7$ & $.6 \wedge \wedge 0$ & $\varepsilon_{6} \ldots$ & T.TV & r.9 & $\varepsilon$ & تلوث المباه \\
\hline גוل & $r_{6} 10 \Lambda$ & $r_{6.7}$ & r.rV & $1,1 \wedge \varepsilon$ & $1 . V T$ & $\varepsilon$ & اختلال التوازن البيئى \\
\hline دال & $r_{6} 1$ & 1. 1 & 17.74 & E.77 & MGGT & r & الارجة الكلية لاختبار \\
\hline
\end{tabular}

يتضح من الجدول السابق لحساب الفروق بين منوسط درجات التطبيق القبلي ومتوسط

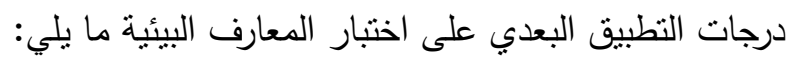

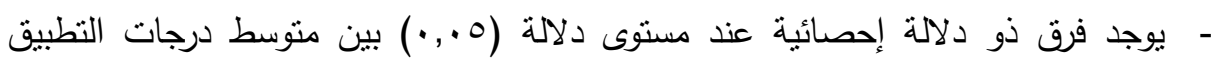

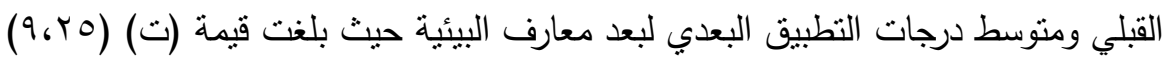

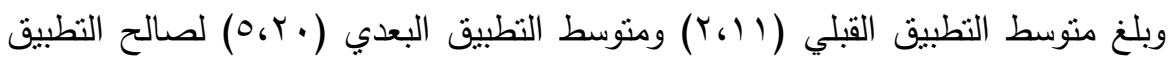

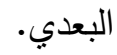
- لا يوجد فرق ذو دلالة إحصائية عند مستوى دلالة (0., •) بين متوسط درجات النطبيق

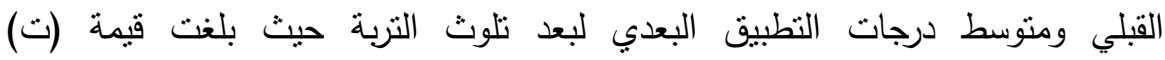


- لا يوجد فروق ذو دلالة إحصائية عند مستوي دلالة (0., •) بين متوسط درجات التطبيق

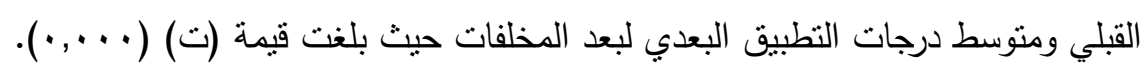

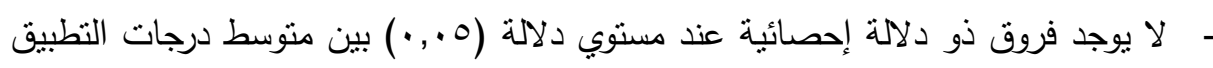

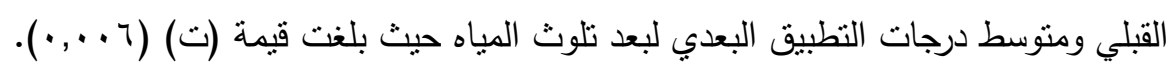

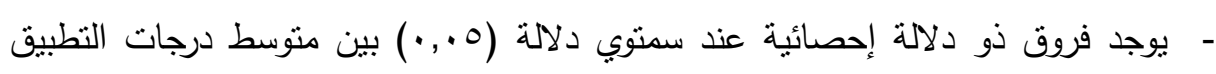

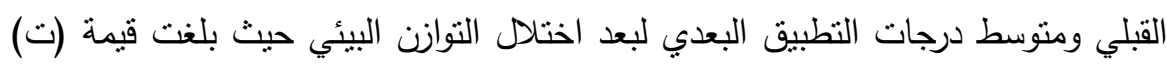

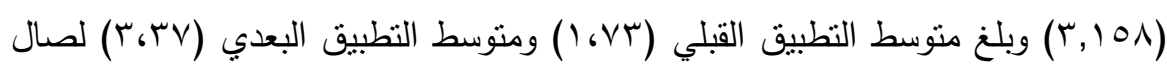
التطبيق البعدي. - يوجد فروق ذو دلالة إحصائية عند مستوي دلالة (ه., •) بين منوسط درجات التطبيق

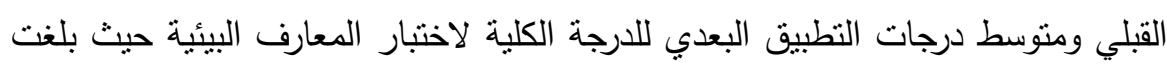

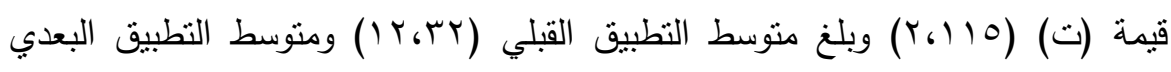

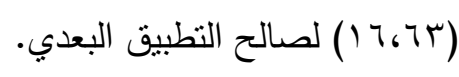

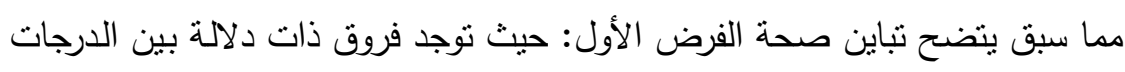

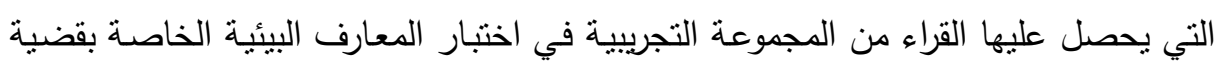
تلوث الهواء وكذللك اختلال التوازن البيئي ولا نوجد في قضية تلوث التربة وكذلك المخلفات

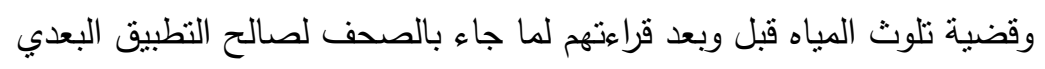


ثانياً: نتائج تطبيق مقياس الاتجاهات البيئية جدول(• (1): اختبار (ت) (t-test) لحساب الفروق بين منوسط درجات التطبيق القبلي ومنوسط درجات التطبيق البعدي على مقياس الاتجاهات البيئية

\begin{tabular}{|c|c|c|c|c|c|c|c|}
\hline \multirow{2}{*}{ مستوي } & \multirow{2}{*}{ قتيـة } & \multicolumn{2}{|c|}{ التطبيق البعد } & \multicolumn{2}{|c|}{ التطبيق القبلى } & \multirow{2}{*}{ الاليجة } & \multirow[t]{2}{*}{ أبعاد المقياس } \\
\hline & & $\varepsilon$ & م & $\varepsilon$ & م & & \\
\hline בدال & $1 \varepsilon_{600 Y}$ & $r_{6 . .}$ & $1 \varepsilon_{6} \cdot 1$ & Y $_{6 . Y_{1}}$ & 7.11 & 1. & تلوث الهواء \\
\hline غير & $16 r .9$ & r.r. & $\varepsilon \sigma \varepsilon r$ & 1.07 & $\varepsilon_{6} \wedge r$ & r & تلوث التربة \\
\hline غير & . & r.01 & VGTV & r.IV & $V_{6} \varepsilon r$ & 0 & المخلفات \\
\hline غير & $\cdot 6 乞 \wedge V$ & $16 \varepsilon$ & r.9V & $1 \leq{ }^{\prime} 1$ & $r_{6} \cdot v$ & r & تلوث المياه \\
\hline دال & $V_{6} \wedge r_{q}$ & $.6 \vee \wedge$ & $r_{6} 0$. & •. V. & $16 \ldots$ & r & اختلال التوازن \\
\hline دال & r.910 & $1 r_{6} 9$ & M1, YO & 1.617 & Yr.01 & YY & الدرجة الكلية للققياس \\
\hline
\end{tabular}

يتضح من الجدول السابق لحساب الفروق بين منوسط درجات التطبيق القبلي ومنوسط درجات التطبيق البعدي على مقياس الاتجاهات البيئية ما يلي: - - يوجد فرق ذو دلالة إحصائية عند مستوى دلالة (0.,·) بين منوسط درجات التطبيق القبلي ومتوسط درجات النطبيق البعدي لبعد تلوث الهواء حيث بلغت قيمة (ت)

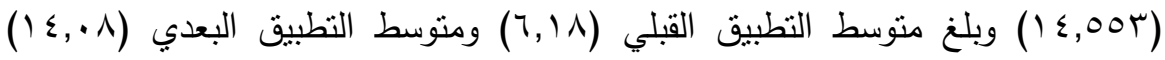
لصالح التطبيق البعدي. - ل لا يوجد فرق ذو دلالة إحصائية عند مستوى دلالة (0., •) بين منوسط درجات التطبيق

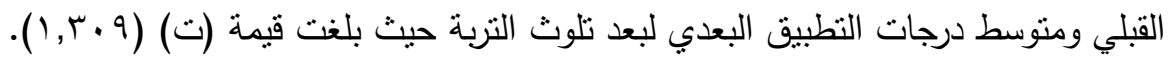
- ل اليوجد فرق ذو دلالة إحصائية عند مستوى دلالة (0., •) بين منوسط درجات النطبيق

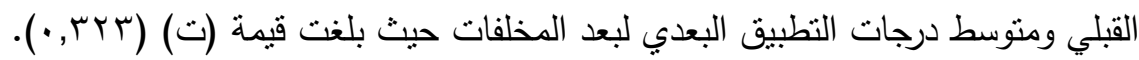
- ل الاوجد فرق ذو دلالة إحصائية عند مستوى دلالة (0.. •) بين منوسط درجات التطبيق

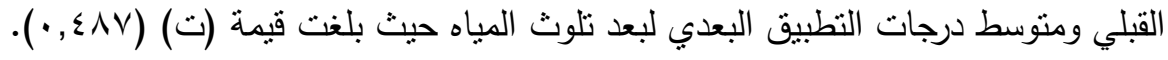

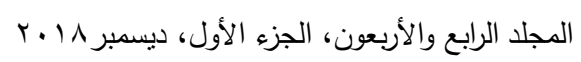


- يوجد فرق ذو دلالة إحصائية عند مستوى دلالة (0., •) بين منوسط درجات التطبيق

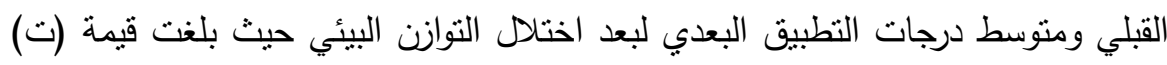

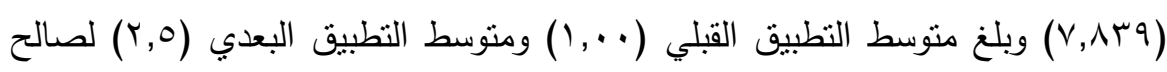
التطبيق البعدي. - يوجد فرق ذو دلالة إحصائية عند مستوى دلالة (0., •) بين متوسط درجات التطبيق

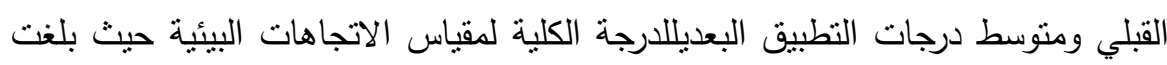

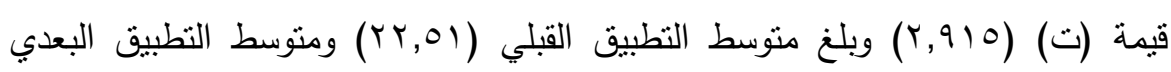

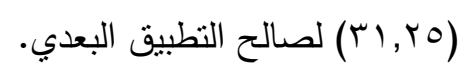
مما سبق يتضح تباين صحة الفرض الثاني: حيث توجد فروق ذات دلالة بين الدرجات

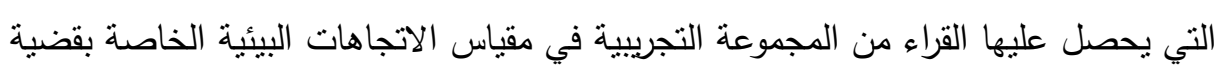
تلوث الهواء وكذلك اختلال التوازن البيئي ولا توجد في قضية تلوث التربة وكذلك المخلفات

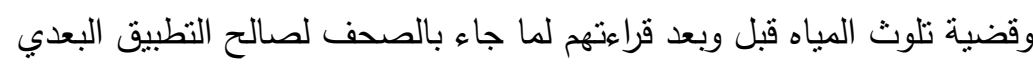

\section{النهوصياهت}

1- تضمين موضوع التتور البيئي بصورة تنتاسب مع الموضوعات المنشورة بشكل دائم

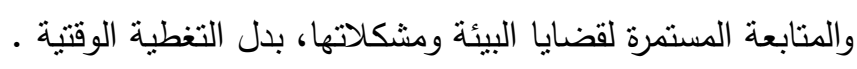
r- تخصيص الصفحة ثابتة ومتخصصة بالبيئة وقضاياها. r- ضرورة وضع استراتيجية الإعلام البيئي وبخاصة الصحافة البيئية.

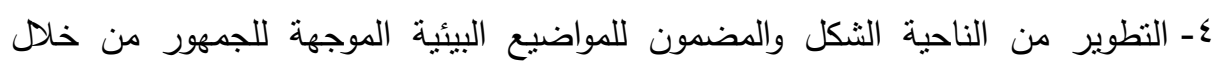
الصحافة.

ه- ضرورة الاستعانة بالخبراء والمختصين في مجال البيئية عند التطرق للموضوعات البيئية.

\section{entl}

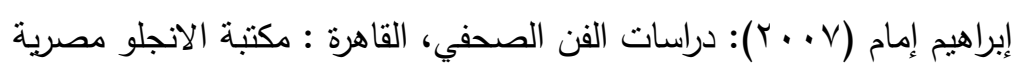

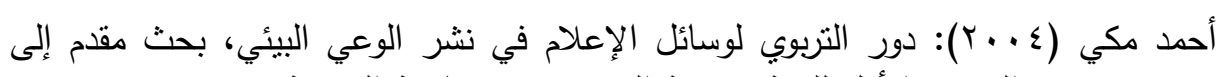

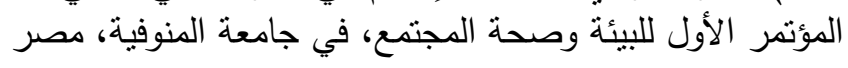




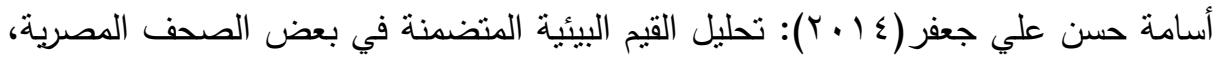

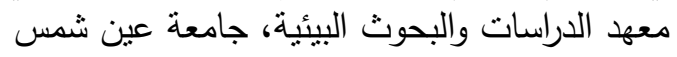

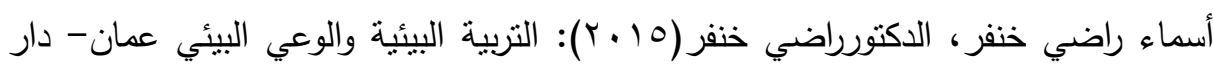
ومكتبة الحامد للنشر والتوزيع

جمال الدين السيد صالح(ץ + . ץ): الإعلام البيئي (بين النظرية والتطبيق)، الإسكندرية، مركز

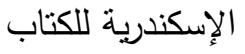

حسن عماد مكاوي، ليلي سيد(· الـ ب): الاتصال ونظرياتة المعاصرة، القاهرة الدار المصرية زهير عبدالطيف، أحمد العبد ابو سعود(؟ (ب)): الاعلام والبيئة، دار اليازوري العلمية

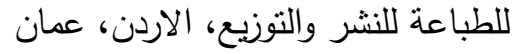

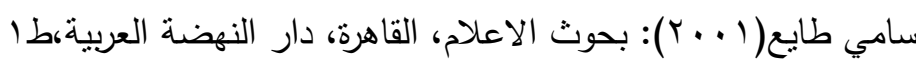
سمير محمد حسين(؟ . . ץ): الرأي العام الاسس النظرية والجوانب المنهجية، القاهرة، عالم الكتب

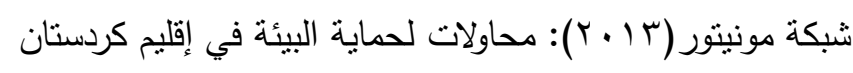

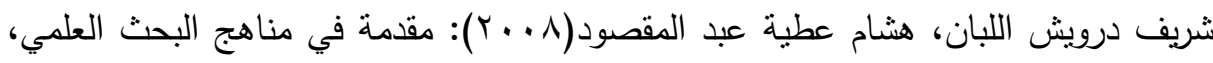

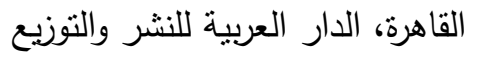

شيماء ذو الفقار زغيب(9 . . r): مناهج البحث والاستخدامات الاحصائية في الدراسات

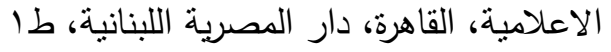

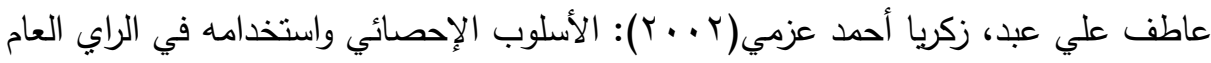
والإعلام، القاهرةن دار الفكر العربي

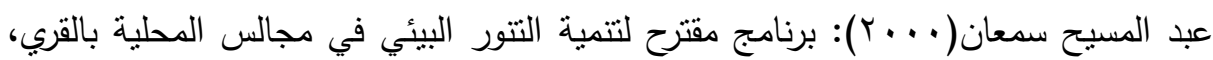

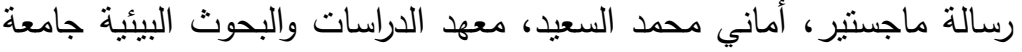

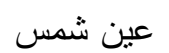

عبد المسيح سمعان: فعالية البرنامج تتمية التتور البيئي لدي معلمي العلوم بالمرحلة الإعدادية

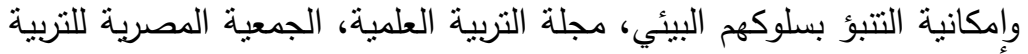

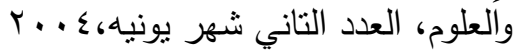

علي عجوه(؟ ـ . ץ): الإعلام والقضايا التتمية، القاهرة، عالم الكتب، طب

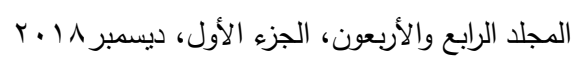


غازي ابوشقرا، المشاكل البيئة التربوية علي المستوبين الدولي والعربي، التربية الجديدة، مجلد TrT. 6197

لاسيول(1 9 (1): تخطيط وتصميم الوسائل الإعلامية.

محسن محمد قادر (9 . . ب): التربية والوعي البيئي واثر الضريبة في الحد من التلوث البيئي،

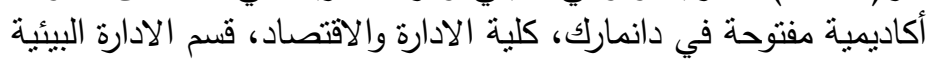

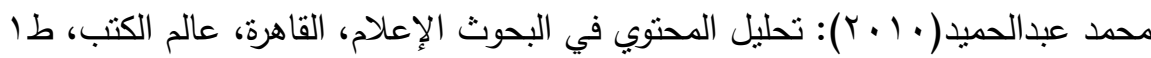

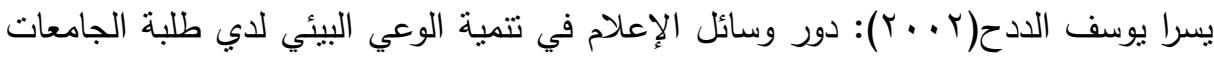

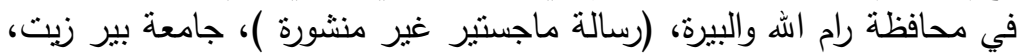
رام الله

Disingr.john.F and Roth Charles E.(1992): Updated june (2003): Environmental literacy ERIC /csmee Digest ERIC clearing Hous for science Mathematics and Environmental Education (ERIC-NO ED 351201).

Krathwohl D.R (1964): Taxonomy of Education objective, hand Book 2 , the effective Domain, Newyork. 
مجلة العلوم البيئية

معهد الدراسات والبحوث البيئية - جامعة عين شمس لئس

\title{
THE ROLE OF PRESS IN DEVELOPING THE ENVIRONMENTAL LITERACY AMONG SECTIONS OF THE PUBLIC FROM KURDISTAN REGION-IRAQ
}

Shaker, Ikhter, A. ${ }^{(1)}$; Abdel Messeih, A. S. ${ }^{(2)}$ and Ali, R. K. ${ }^{(3)}$

1) The Relations and Information Department, Ministry of Culture and Youth, Kurdistan Province, Iraq 2) Institute of Environmental Studies Research, Ain shams University 3) Faculty of Information, Salahaldin University In Arbil Kurdistan, Iraq

\begin{abstract}
The study aimed to analyze the environmental issues in some Kurdish newspapers in Kurdistan, as well as the effectiveness of the press to address the issues and environmental issues on the development of the environmental enlightenment of the readers. Therefore, the researchers prepared a form to analyze the content of some newspapers sample study, The Huller-Kordestani-Noe Journal was analyzed between January 2015 and December 2015, and the Environmental Enrichment Scale was applied before and after reading the environmental issues imported in the two study journals. The study sample was 30 persons. The researchers used descriptive and semiexperimental approaches.

The researchers found that there was a difference in the interest of the newspapers in the study sample on environmental issues. There were also statistically significant differences in the scores obtained by the study sample members in the environmental enlightening scale in some environmental issues before and after the study sample was subjected to a sample written by the newspapers.

Which indicates the difference in the effectiveness of newspapers in the development of environmental enlightenment to readers.
\end{abstract}

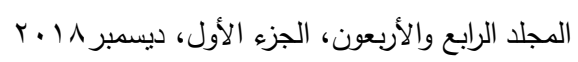


The researchers recommended that the Kurdish newspapers should deal with the effective treatment of environmental issues, which is reflected in the environmental degradation of the readers. 